Cronfa - Swansea University Open Access Repository

This is an author produced version of a paper published in :

Ergonomics

Cronfa URL for this paper:

http://cronfa.swan.ac.uk/Record/cronfa22100

\title{
Paper:
}

Vedaa, Ø., Harris, A., Bjorvatn, B., Waage, S., Sivertsen, B., Tucker, P. \& Pallesen, S. (in press). Systematic review of the relationship between quick returns in rotating shift work and health-related outcomes. Ergonomics, 1-45.

http://dx.doi.org/10.1080/00140139.2015.1052020

This article is brought to you by Swansea University. Any person downloading material is agreeing to abide by the terms of the repository licence. Authors are personally responsible for adhering to publisher restrictions or conditions. When uploading content they are required to comply with their publisher agreement and the SHERPA RoMEO database to judge whether or not it is copyright safe to add this version of the paper to this repository. http://www.swansea.ac.uk/iss/researchsupport/cronfa-support/ 
This article was downloaded by: [Philip Tucker]

On: 17 June 2015, At: 02:31

Publisher: Taylor \& Francis

Informa Ltd Registered in England and Wales Registered Number: 1072954 Registered office: Mortimer House, 37-41 Mortimer Street, London W1T 3J H, UK

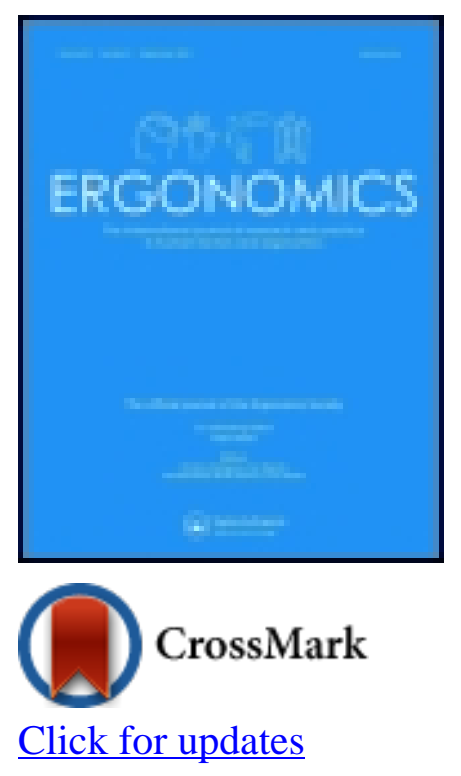

\title{
Ergonomics
}

Publication details, including instructions for authors and subscription information:

http:// www. tandfonline.com/loi/terg20

\section{Systematic review of the relationship between quick returns in rotating shift work and health-related outcomes}

\author{
Øystein Vedaa ${ }^{a b}$, Anette Harris ${ }^{c}$, Bjørn Bjorvatn $^{\text {de }}$, Siri Waage ${ }^{\text {de }}$, Børge Sivertsen ${ }^{b}$, Philip \\ Tucker $^{\text {fg }} \&$ Ståle Pallesen ${ }^{\text {ae }}$ \\ a Department of Psychosocial Science, University of Bergen, Christiesgt. 125015, Bergen, \\ Norway \\ ${ }^{b}$ Division of Mental Health, Norwegian Institute of Public Health, Kalfarveien 31, 5018, \\ Bergen, Norway \\ ${ }^{c}$ Department of Health Promotion and Development, University of Bergen, Christiesgt. 13, \\ 5015, Bergen, Norway \\ ${ }^{d}$ Department of Global Public Health and Primary Care, University of Bergen, Kalfarveien \\ 31, 5018, Bergen, Norway \\ ${ }^{\mathrm{e}}$ Norwegian Competence Center for Sleep Disorders, Haukeland University Hospital, J onas \\ Lies vei 65, 5021, Bergen, Norway \\ ${ }^{f}$ Stress Research Institute, Stockholm University, SE-106 91, Stockholm, Sweden \\ ${ }^{9}$ Department of Psychology, Swansea University, Swansea, SA2 8PP, United Kingdom \\ Accepted author version posted online: 15 J un 2015.
}

To cite this article: Øystein Vedaa, Anette Harris, Bjørn Bjorvatn, Siri Waage, Børge Sivertsen, Philip Tucker \& Ståle Pallesen (2015): Systematic review of the relationship between quick returns in rotating shift work and health-related outcomes, Ergonomics, DOI: 10.1080/00140139.2015.1052020

To link to this article: http:// dx. doi.org/ 10.1080/00140139.2015.1052020

Disclaimer: This is a version of an unedited manuscript that has been accepted for publication. As a service to authors and researchers we are providing this version of the accepted manuscript (AM). Copyediting, typesetting, and review of the resulting proof will be undertaken on this manuscript before final publication of the Version of Record (VoR). During production and pre-press, errors may be discovered which could affect the content, and all legal disclaimers that apply to the journal relate to this version also.

\section{PLEASE SCROLL DOWN FOR ARTICLE}

Taylor \& Francis makes every effort to ensure the accuracy of all the information (the "Content") contained in the publications on our platform. However, Taylor \& Francis, our agents, and our licensors make no representations or warranties whatsoever as to the accuracy, completeness, or suitability for any purpose of the Content. Any opinions and views expressed in this publication are the opinions and views of the authors, and are not the views of or endorsed by Taylor \& Francis. The accuracy of the Content should not be relied upon and should be independently verified with primary sources of information. Taylor and Francis shall not be liable for any losses, actions, claims, proceedings, demands, costs, expenses, damages, and other liabilities whatsoever or howsoever caused arising directly or indirectly in connection with, in relation to or arising out of the use of the Content. 
This article may be used for research, teaching, and private study purposes. Any substantial or systematic reproduction, redistribution, reselling, loan, sub-licensing, systematic supply, or distribution in any form to anyone is expressly forbidden. Terms $\&$ Conditions of access and use can be found at http:// www.tandfonline.com/page/terms-and-conditions 
Publisher: Taylor \& Francis

Journal: Ergonomics

DOI: http://dx.doi.org/10.1080/00140139.2015.1052020

Title: Systematic review of the relationship between quick returns in rotating shift work and health-related outcomes

Running head: Quick returns and health-related outcomes

Øystein Vedaa PsyD ${ }^{\mathrm{a}, \mathrm{b}}$, Anette Harris $\mathrm{PhD}^{\mathrm{c}}$, Bjørn Bjorvatn $\mathrm{PhD}^{\mathrm{d}, \mathrm{e}}$, Siri Waage $\mathrm{PhD}^{\mathrm{d}, \mathrm{e}}$,

Børge Sivertsen $\mathrm{PhD}^{\mathrm{b}}$, Philip Tucker $\mathrm{PhD}^{\mathrm{f}, \mathrm{g}}$, Ståle Pallesen $\mathrm{PhD}^{\mathrm{a}, \mathrm{e}}$

${ }^{a}$ Department of Psychosocial Science, University of Bergen, Christiesgt. 12, 5015

Bergen Norway

${ }^{\mathrm{b}}$ Division of Mental Health, Norwegian Institute of Public Health, Kalfarveien 31, 5018

Bergen, Norway

${ }^{\mathrm{c}}$ Department of Health Promotion and Development, University of Bergen, Christiesgt.

13, 5015 Bergen, Norway

${ }^{\mathrm{d}}$ Department of Global Public Health and Primary Care, University of Bergen,

Kalfarveien 31, 5018 Bergen, Norway

${ }^{\mathrm{e}}$ Norwegian Competence Center for Sleep Disorders, Haukeland University Hospital, Jonas Lies vei 65, 5021 Bergen, Norway

${ }^{\mathrm{f}}$ Stress Research Institute, Stockholm University, SE-106 91 Stockholm, Sweden

${ }^{\text {g }}$ Department of Psychology, Swansea University, Swansea SA2 8PP, United Kingdom

Contact information:

Øystein Vedaa (corresponding author) (oystein.vedaa@psysp.uib.no, phone +4755 5833

05). Department of Psychosocial Science, University of Bergen, Christiesgt. 12, 5015

Bergen Norway

Anette Harris (anette.harris@uih.uib.no, phone +47 555832 19), Bjørn Bjorvatn

(bjorn.bjorvatn@igs.uib.no, phone +47 555860 88), Siri Waage (iri.waage@igs.uib.no, phone +47 555860 64), Børge Sivertsen (borge.sivertsen@fhi.no, phone +47 532041 
01), Philip Tucker (p.t.tucker@swansea.ac.uk, phone +44 (0) 1792 295896), Ståle Pallesen (staale.pallesen@psysp.uib.no, phone +47 555888 42).

\section{Abstract}

A systematic literature search was carried out to investigate the relationship between quick returns (i.e., 11.0 hours or less between two consecutive shifts) and outcome measures of health, sleep, functional ability and work-life balance. A total of 22 studies published in 21 articles were included. Three types of quick returns were differentiated (from evening to morning/day, night to evening, morning/day to night shifts) where sleep duration and sleepiness appeared to be differently affected depending on which shifts the quick returns occurred between. There were some indications of detrimental effects of quick returns on proximate problems (e.g., sleep, sleepiness and fatigue), although the evidence of associations with more chronic outcome measures (physical and mental health and work-life balance) was inconclusive.

Key words: Quick return, Quick changeover, Short changeover, Short recovery

\section{Practitioner summary}

Modern societies are dependent on people working shifts. This study systematically reviews literature on the consequences of quick returns (11 hours or less between two shifts). Quick returns have detrimental effects on acute health problems. However the evidence regarding effects on chronic health is inconclusive. 


\section{Introduction}

Shift work is a way of organizing working time where 'workers succeed one another at the workplace so that the total operation hours exceed the hours of work carried out by individual workers’ (ILO 1995, p.14). Increasing use of shift work and irregular work hours are believed to be driven by major societal changes with a decline in manufacturing and the rise in the service economy (Johnson and Lipscomb 2006). However, shift work often disrupts the alignment between external demands and the individuals' internal circadian rhythm. This biorhythmic disruption is believed to be an important contributor to the increased risk of various sleep difficulties (Åkerstedt 2003) and negative health effects associated with shift work such as breast cancer, cardiovascular disease, diabetes, obesity, gastro-intestinal problems and peptic ulcer disease, among others (Baron and Reid 2014, Monk and Buysse 2013, Costa, Haus, and Stevens 2010, Gan et al. 2014, Knutsson and Bøggild 2010, Vyas et al. 2012, Wang et al. 2011). Furthermore, there is evidence to suggest that shift work may impair mental wellbeing and increases the risk for psychological distress (Vogel et al. 2012, Baron and Reid 2014). It has been suggested that some of the effects of shift work on mental health may be mediated by social difficulties in terms of imbalance between work and private life (Haines et al. 2008). Shift work has also been inferred as a risk factor for sick leave; currently, however, this seems primarily to apply to female healthcare workers on fixed evening work (Merkus et al. 2012). One recent study also indicated that shift work was associated with a chronic impairment of cognition (Marquié et al. 2014). 
Some shift schedules are believed to affect workers' health to a greater extent than others. Night and early morning shifts cause the largest biorhythmic disruption and have accordingly been associated with the largest effects on sleep and health (Åkerstedt 2003, Sallinen and Kecklund 2010). A number of other shift characteristics have also been shown to impact sleep and health, such as the length of the shift (e.g., $8 \mathrm{~h}$ or $12 \mathrm{~h}$ shifts) (Lowden et al. 1998), type of shift schedule, and direction and speed of rotation (Tucker et al. 2000, Barton and Folkard 1993). An important aspect with rotating shifts concerns to what extent the time between shifts facilitates adequate rest. Quick returns refers to changeovers from evening to morning/day shifts, night to evening shifts, or morning/day to night shifts, where 11.0 hours or less free time are scheduled between shifts (European Parliament 2003). Although there are no statistics on the prevalence of quick returns, one survey on Norwegian nurses found that $81.2 \%$ reported exposure to quick returns in the past year $(n=1990$; mean annual number of quick returns $=33.2)$ (Eldevik et al. 2013). Although 11.0 hours between shifts defines the upper duration of time off for quick returns, the number of hours between two shifts is often far less. The actual time for rest may be further shortened by long commutes, time for self-care and domestic chores, which consequently may result in substantial sleep deficiency in quick returns (Kecklund and Åkerstedt 1995), again possibly affecting wellbeing and health. Consequently, it is recommended that shift schedules should not feature quick returns (Knauth 1996, Kecklund and Åkerstedt 1995). This is also reflected in the recommendations of the European Working Time Directive, which emphasizes that workers are entitled to a minimum daily rest period of 11.0 consecutive hours per 24.0-hour period (European Parliament 2003). 
Recent studies have shown that the effects of quick returns on sleep and fatigue can be equally severe as, or even more severe than, those of night shifts (Eldevik et al. 2013, Flo et al. 2014). Such findings highlight the need to examine the wider potential impact of quick returns. While the consequences of quick returns have been examined in previous reviews to some extent (Knauth 1996, Sallinen and Kecklund 2010, Keckklund and Åkerstedt 1995, Åkerstedt 2003), none of these reviews focused exclusively on quick returns and none used a systematic approach. The current study addresses these shortcomings by conducting a systematic literature search with the aim of consolidating the evidence on the relationship between quick returns and outcome measures ranging from health, sleep, functional ability and work-life balance.

\section{Methods}

Systematic searches were carried out in order to identify relevant studies for this literature review. The search combined the keywords "shift work*" OR shiftwork* OR "night work*" OR nightshift* OR "night shift*" with various thesaurus-obtained terms for quick return; including "quick return*" OR "quick change over" OR "short off-duty" OR "short turn-around*” OR "quick turn-around*" OR "short turnaround" OR "quick turnaround" OR "quick shift-change period*” OR "short rest" OR "short break*" OR "short free time" OR recovery OR "short sleep" OR "restricted sleep" OR advan* OR rotat*. The searches were conducted in the databases Web of Science, Pubmed and PsycINFO and resulted in 1214, 1100, and 455 hits, respectively. An overview of the search and selection process is presented in Figure 1. No year restriction was used and the searches were carried out throughout October 2014. The total number of hits after sorting for document type article and deleting duplicates was 1839. The search strategy 
and selection of eligible studies were carried out by a single reviewer (first author). The articles were first screened for relevance by reading the title alone - a recently validated approach (Mateen et al. 2013) - which led to an initial rejection of 1210 articles. This required a further review of 629 abstracts, and finally 78 full text articles were studied. Forward citation searches were used to track down references cited by relevant sources. Studies eligible for inclusion in the review were evaluated against a set of predefined inclusion criteria. The studies had to be written in English and published in peerreview journals (e.g., governmental reports were excluded). The studies had to report results from data on workers in a naturalistic or simulated shift work setting. Furthermore, the inclusion criteria were quite broad in terms of study design and quality of investigation, in an attempt to provide a complete overview of the limited research done on the subject of quick returns. However, the studies had to use a quantitative design allowing inferences about the association between health-related parameters and quick returns; and quick returns had to be clearly defined as 11.0 hours or less between two shifts. Furthermore, specific restrictions were set regarding split-shifts and sea-watch systems. These are often rotating shifts with less than 11.0 hours off between them, but were deemed different from quick returns due to the fact that these shifts are often substantially shorter and the free period between the shifts are not necessarily used for sleep. Sea-watch systems also occur in a special off-shore context where aspects such as commuting time and domestic demands are more or less eliminated, in contrast to standard land-based shift work.

\section{Results}


In total, 22 studies published in 21 articles were included in this review (Table 1). Taken together these studies included 14028 subjects in which the weighted average age was 38.5 years (from the 16 studies that reported age). Eight studies were cross-sectional survey studies (Barton and Folkard 1993, Eldevik et al. 2013, Flo et al. 2012, GeigerBrown, Trinkoff, and Rogers 2011, Kandolin and Huida 1996, Tucker et al. 2000, Tucker et al. 2010, Tucker et al. 2015), one was a longitudinal survey study (Flo et al. 2014), three were intervention studies (where quick returns were reduced or abolished) (Hakola, Paukkonen, and Pohjonen 2010, Kandolin and Huida 1996, Lowden et al. 1998), five were field studies (data collection over time in natural settings) (Axelsson et al. 2004, Sallinen et al. 2003, Signal and Gander 2007, Karhula et al. 2013, Costa et al. 2014), one was a field study which included laboratory assessments (Härmä et al. 2002) and one was a pure laboratory study (Cruz et al. 2003), one was a registry study (analyzed objective records from an injury report database) (Macdonald et al. 1997), and two studies labeled themselves as time-budget studies (i.e., they employed time-use diaries to identify activities occupying each hour of each day for a fixed period of time) (Knauth et al. 1983, Kurumatani et al. 1994). Most of the studies were based on self-report diaries and a mixture of standardized questionnaires and unstandardized questions (Barton and Folkard 1993, Eldevik et al. 2013, Flo et al. 2012, Geiger-Brown, Trinkoff, and Rogers 2011, Kandolin and Huida 1996, Tucker et al. 2000, Flo et al. 2014, Lowden et al. 1998, Karhula et al. 2013, Sallinen et al. 2003, Signal and Gander 2007, Härmä et al. 2002, Cruz et al. 2003, Kurumatani et al. 1994, Knauth et al. 1983, Hakola, Paukkonen, and Pohjonen 2010, Tucker et al. 2010, Tucker et al. 2015). Three studies used actigraphy recordings to monitor sleep and activity objectively (Axelsson et al. 2004, Signal and 
Gander 2007, Costa et al. 2014), and one used objective records of injuries from the medical department at the workplace (Macdonald et al. 1997).

\subsection{Sleep duration and disturbed sleep}

The most common quick return appears to occur between evening and the following morning/day shifts (Table 2.). Three field studies (Axelsson et al. 2004, Sallinen et al. 2003, Costa et al. 2014), one time-budget study (Knauth et al. 1983) and one intervention study (Hakola, Paukkonen, and Pohjonen 2010) found that quick returns between evening and morning/day shifts caused shorter sleep duration. Quick returns between night and evening shifts was found to shorten sleep duration in one field study (Axelsson et al. 2004). The sleep/nap between morning/day and night shifts was investigated in one timebudget study (Kurumatani et al. 1994), one field study (Costa et al. 2014) and two laboratory studies (Signal and Gander 2007, Cruz et al. 2003). Although this sleep appeared to have a short duration (Table 2.), Cruz et al. (Cruz et al. 2003) argued that this sleep should be viewed as a nap that add to the major sleep period prior to the morning/day shift. Their analysis showed no significant differences between advancing (with quick returns) and delaying (without quick returns) shift rotations in terms of sleep duration when the nap before the night shift was combined with the major sleep period (Cruz et al. 2003). Furthermore, sleep duration appeared to increase the first night after a quick return, which is attributed to the need to recover from the quick returns (Tucker et al. 2000, Axelsson et al. 2004).

An overview of the association of quick returns and health related outcome beyond sleep duration is provided in Table 3. One field study showed that nurses reported significantly lower sleep quality after quick returns of 10.0 hours from evening to 
morning shifts in an 8-hour system, compared to those with longer changeovers in a 12hour system (Costa et al. 2014). One cross-sectional study showed that quick returns of 10.0 hours were positively associated with more frequent reports of inadequate and restless sleep among nurses (Geiger-Brown, Trinkoff, and Rogers 2011). Three survey studies support a positive association between quick returns and shift work disorder (Eldevik et al. 2013, Flo et al. 2014, Flo et al. 2012), of which one was a longitudinal study (Flo et al. 2014). One cross-sectional study also showed a positive association between quick returns and insomnia (Eldevik et al. 2013). In these survey studies exposure to quick returns were defined as occurrence within the last month (GeigerBrown, Trinkoff, and Rogers 2011) or frequency last year (Eldevik et al. 2013, Flo et al. 2014, Flo et al. 2012). These survey studies did not report between which shifts the quick returns occurred. In contrast to these findings, however, one cross-sectional survey found that workers on a shift system with quick returns reported less sleep disturbances than workers on a system without (Barton and Folkard 1993).

\subsection{Sleepiness and fatigue}

The presence of quick returns from evening to morning/day shifts and night to evening shifts were associated with increased sleepiness in five studies (Axelsson et al. 2004, Eldevik et al. 2013, Flo et al. 2014, Karhula et al. 2013, Costa et al. 2014) and increased fatigue in six studies (Knauth et al. 1983, Flo et al. 2014, Eldevik et al. 2013, Barton and Folkard 1993, Lowden et al. 1998, Tucker et al. 2010). Two intervention studies found that reduction in the number of quick returns of 9.0 hours between evening and morning shifts improved self-reported sleep and alertness (Hakola, Paukkonen, and Pohjonen 2010) and caused less tiredness compared to a control group (Kandolin and Huida 1996). 
It should however be noted that the intervention in the latter study consisted of both reducing quick returns and increasing personal involvement in shift planning, thus it was not possible for the authors to separate the effect of the two parallel interventions (Kandolin and Huida 1996). One survey study suggested quick returns of 8.0 hours (from night to evening and morning to night shifts) as the likely cause of a marginally more rapid decline in workers self-report alertness levels over the duration of a shift, compared to shift systems without quick returns (Tucker et al. 2000). One study used archival accident records to compare two shift systems which differed with respect the presence of a quick return of 8.0 hours between the night and evening shifts (Macdonald et al. 1997). Risk for accidents appeared to be higher during evening shifts that followed a quick return, which was initially interpreted as a detrimental effect of quick returns on risk for accidents (Macdonald et al. 1997). However, it was subsequently suggested by one of the study's authors that the difference may have been attributable to the different shift sequences of the two shift systems (Spencer, Robertson, and Folkard 2006).

Two field studies have investigated sleepiness and quick returns from morning/day to night shifts. One found quick returns of 10.0 hours in a 8-hour system to increase sleepiness compared to longer changeovers in a 12-hour system (Costa et al. 2014). The other found quick returns of 8.0 hours or less represented a smaller risk for sleepiness than a changeover period of 16.0 hours or more (Härmä et al. 2002). The latter observation was believed to be due to the fact that a significantly larger proportion of people with quick returns took naps before night work compared to those with longer changeover periods (Härmä et al. 2002, Cruz et al. 2003). In addition, the nap between morning/day and night shifts in quick returns tends to be of longer duration (2.8 hours) 
compared to those with longer changeover periods to the night shifts (1.9 hours) (Cruz et al. 2003).

\subsection{General health and wellbeing}

Quick returns were positively associated with self-reported stress in one cross-sectional study (Tucker et al. 2015). Two intervention studies found that reduction of quick returns of 9.0 hours from evening to morning shifts led subjects to report better general health and social wellbeing (Hakola, Paukkonen, and Pohjonen 2010) as well as less mental strain and stress (Kandolin and Huida 1996). The former study did however not find any effects of reduction of quick returns in terms of reported occurrence of diseases or sickness absence (Hakola, Paukkonen, and Pohjonen 2010). One survey study found that workers on a shift system with quick returns reported poorer physical health than among those on systems without quick returns (Barton and Folkard 1993). However, this was not observed in another survey study comparing workers on a shift system which included quick returns of 8.0 hours (from night to evening and morning to night shifts) to those on other systems without quick returns (Tucker et al. 2000). In addition, three survey studies, of which one was longitudinal, did not find any associations between quick returns and measures of mental health (Flo et al. 2014, Eldevik et al. 2013, Barton and Folkard 1993), nor did changes in the number of quick returns have any effect on reported symptoms of depression or anxiety over time (Flo et al. 2014).

One survey study found that workers on a shift system with quick returns reported more social and domestic disruption and less job satisfaction, than those working on a shift system without quick returns (Barton and Folkard 1993). In one intervention study, reduction of quick returns of 9.0 hours between evening and morning shifts improved the 
workers self-reported wellbeing at work and their leisure time activities (Hakola, Paukkonen, and Pohjonen 2010). The reduction of quick returns in this study also led workers to report higher mental work ability, although there were no significant changes on the more general work ability index (Hakola, Paukkonen, and Pohjonen 2010). In one intervention study, reduction of quick returns of 9.0 hours between evening and morning shifts improved the social climate at work regarding support from supervisors and relationship with colleagues (Kandolin and Huida 1996). As pointed out earlier, the intervention in the latter study also included increased personal involvement in shift planning that unfortunately represents an obvious confounding variable. Reduction of quick returns of 9.0 hours from evening to morning shifts in another intervention study did not have any effect on the workers’ social and family life (Hakola, Paukkonen, and Pohjonen 2010). No negative effect was observed on self-reported social and domestic disruption in a cross-sectional study comparing workers on a shift system which included quick returns of 8.0 hours (from night to evening and morning to night shifts) to those on other systems without quick returns (Tucker et al. 2000).

\section{Discussion}

The aim of this review was to synthesize evidence on the relationship of quick returns (i.e., a break between shifts of 11.0 hours or less) and health-related outcomes. It is reasonable to expect that limited time for rest between shifts will impose a corresponding shortening of sleep duration. In most cases, quick returns involve short rests of 8.0 or 9.0 hours between shifts. The actual time for rest between the shifts may however be significantly shorter than this, when subtracting actual time for departure from work, long commutes, time to unwind before sleep, and to eat and freshen up before the next shift. 
Time-use studies have shown that social- and leisure activities remain a priority for individuals and are likely to be exchanged for sleep time (Basner et al. 2007). Domestic chores may further shorten the time for sleep in quick returns, which may affect female workers more than men due to gender inequality in households (Rotenberg et al. 2008, Silva, Rotenberg, and Fischer 2011). In line with this, the result from this review indicated a shortening of sleep duration to 6.5 hours or less with quick returns. Previous studies have shown that repeated restriction of sleep to 6.0 hours or less per night substantially impairs neurobehavioral functions (Van Dongen et al. 2003). This is of particular concern, given that the typical occupations exposed to quick returns are within health care, industrial production facilities, transport industry and aviation, where high levels of cognitive functions are critical for safety and where lapses in attention easily can have fatal outcomes. However, few studies have investigated partial sleep deprivation that occurs at intermittent intervals, as is often the case with quick returns. Although one study appeared to suggest detrimental effects of quick returns on risk for accidents (Macdonald et al. 1997), a retrospective re-analysis of the results have called into doubt that interpretation of the findings (Spencer, Robertson, and Folkard 2006).

Sleep duration appeared to be differently affected depending on which shifts the quick returns occur between. The results from this review indicate that while the shortest sleep durations seemed to occur between morning/day and night shifts, somewhat longer sleeps took place between night and evening shifts and the longest sleeps were between evening and morning/day shifts. This is consistent with the fact that the time for rest between shifts in the three types of quick returns occurs at different points within the circadian rhythm and the homeostatic sleep drive. The free periods associated with the 
three types of quick returns fall during the evening, day and night, respectively. The desire and the possibility to spend the free time asleep may also be less during daytime or evening, due to social and family activities, as in the case with the free periods between night to evening and morning/day to night shifts. A night shift followed by an evening shift may be the worst quick return in terms of sleep deficit (Kecklund and Åkerstedt 1995). Sleep is rapidly initiated after a night shift, but often difficult to maintain compared to a normal night's sleep

口kerstedt, Kecklund, and Knutsson 1991). The

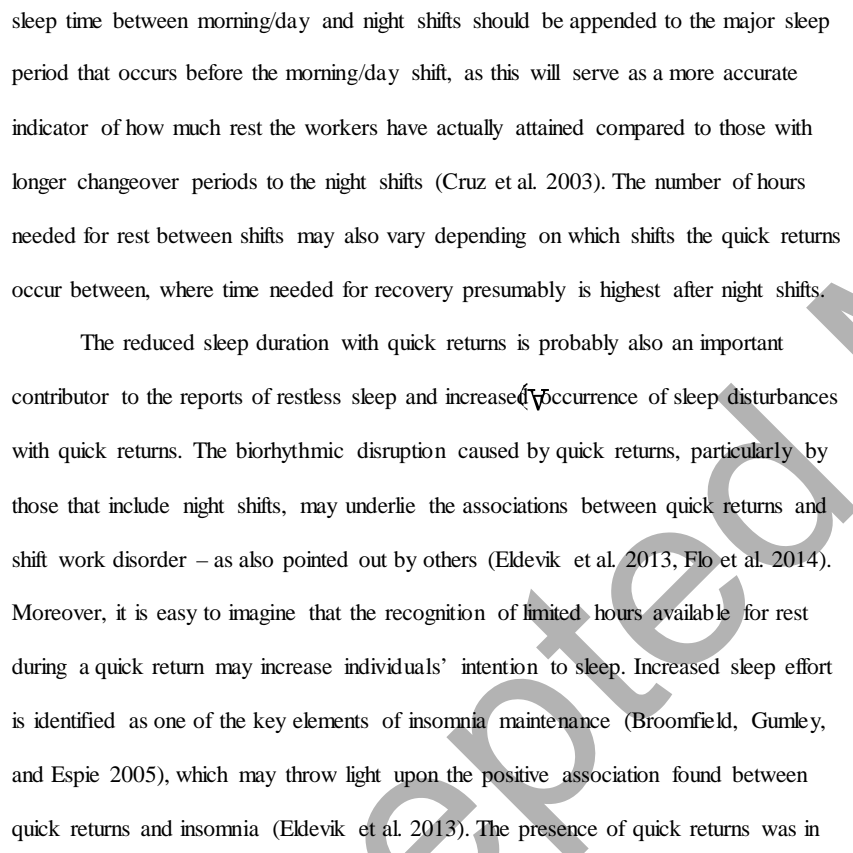


most studies associated with increased sleepiness and fatigue, which highlight the need for more time to recover between shifts. One exception however was quick returns from morning/day to night shifts, which in one study was suggested to reduce the risk for sleepiness during the night shifts (Härmä et al. 2002). This was believed to be due to the more frequent and longer sleeps/naps taken by the workers before the night shifts during quick returns, compared to those with longer changeover periods before the night shifts (Härmä et al. 2002, Cruz et al. 2003). As noted above, this sleep/nap should be appended to the major sleep period, which introduces a more accurate indicator of how much rest the individual actually has attained. These observations nevertheless suggest that a quick return to the night shift may enable more sleep closer to the night shift, which subsequently may enhance the individual's level of functioning on the night shift. Such effects would be consistent with evidence that naps on the night shift improve alertness and functional ability (Ruggiero and Redeker 2014). However, it remains unclear whether these apparent benefits of quick returns to the night shift outweigh any disadvantages of such double shifts, and it should be noted that one study observed increased sleepiness with these quick returns (Costa et al. 2014).

The consequences of shift work on physical and mental health-related outcomes are widespread and well documented (Baron and Reid 2014, Monk and Buysse 2013, Costa, Haus, and Stevens 2010, Gan et al. 2014, Knutsson and Bøggild 2010, Vyas et al. 2012, Wang et al. 2011, Vogel et al. 2012). The mechanisms believed to underlie the negative health outcomes of shift work include biorhythmic disruption and sleep deprivation (Knutsson 2003), both of which are also present with quick returns. There were some indications of better general health and wellbeing when fewer quick returns 
were introduced in an intervention study, but no substantial changes in occurrence of diseases or sickness absence (Hakola, Paukkonen, and Pohjonen 2010). In terms of mental health, there were consistent reports of no relations with exposure to quick returns (Flo et al. 2014, Eldevik et al. 2013, Barton and Folkard 1993). Taken together there is as of yet no clear indication of quick returns as a substantial risk factor for physical or mental health-related problems. Needless to say, more research is warranted before firm conclusions can be drawn on this matter. Meanwhile, many workers are supportive of quick returns due to the longer consecutive free periods they generate (Kandolin and Huida 1996, Schroeder, Rosa, and Witt 1998). It is a matter of speculation as to whether the cost of enduring quick returns on chronic outcome measures - such as physical and mental health - may be equalized by the recovery gained from the extra free time it contributes to.

Work outside regular daytime has been found to complicate family and private life activities (Albertsen et al. 2008). Overall, most reports on the balance between work and private life in this review portray quick returns as an unfavorable shift characteristic (Barton and Folkard 1993, Hakola, Paukkonen, and Pohjonen 2010, Kandolin and Huida 1996). However, some of the results indicated no effect of quick returns on social and family life (Hakola, Paukkonen, and Pohjonen 2010). The results from one study are difficult to interpret due to a parallel intervention with increased personal involvement in shift planning (Kandolin and Huida 1996), and not all studies found an effect of quick returns on work-life balance (Tucker et al. 2000). In an intervention study that aimed at increasing work-life balance, it appeared that more work time control and the ability to adjust working hours to personal needs were more important for the work-life balance- 
related measures than actual changes in working hours (Albertsen et al. 2014). Taken together, there is little evidence to conclude on the relation between quick returns and work-life balance. The ambiguity in the studies may reflect the fact that despite the proximate problems associated with quick returns, the workers seem to favor the longer free periods it generates (Kandolin and Huida 1996, Schroeder, Rosa, and Witt 1998). For example, the midwives studied by Kandolin and Huida (1996) reported that the longer free periods accumulated due to quick returns made it easier to combine shift work and social life.

\subsection{Limitations and further direction}

A potential limitation is that, while the inclusion criteria were agreed by all authors, only one of the authors conducted the literature search (first author). In mitigation, it should be noted that previous research has shown that single reviewers on average miss less than 10 percent of eligible reports (Edwards et al. 2002). Relevant findings may have been lost due to stringent inclusion criteria; for example, some studies were deemed relevant by content but excluded due to the fact that they were not published in peer review journals (Saito and Kogi 1978, Della Rocco and Cruz 1995, 1996, Cruz and Della Rocco 1995, Schroeder, Rosa, and Witt 1995). Relevant studies may also have been excluded prematurely after reading the abstract in cases where quick returns were not highlighted in the abstract. However, forward citation searches were carried out that may have intercepted important studies where this was the case. Another limitation with this review, which also reflects a limitation in the literature, pertains to the fact that quick returns are often defined as short rest of 11.0 hours or less between shifts. Since workers 
are entitled to a minimum daily rest period of 11.0 hours (European Parliament 2003) it seems more correct to define quick returns as less than 11.0 hours in future studies.

In general, the predominance of cross-sectional studies of quick returns is a limitation as it precludes inferences about causality. There is also a predominance of female subjects due to the large survey studies on health personnel (Geiger-Brown, Trinkoff, and Rogers 2011, Flo et al. 2014). This may reflect a bias within the field since research results are not always generalizable between the sexes (Holdcroft 2007). Many studies also rely on subjective measures, which increases the risk for systematic errors due to inaccurate recollections and other biases related to subjective reports (Weiss 1995, Podsakoff et al. 2003). Furthermore, quick returns were often not the primary target for investigation in studies but nevertheless suggested as an explanatory factor. The study designs are thus not always ideal to make inferences about the specific ramifications of quick returns, primarily due to rudimentary definitions of quick returns and lack of control over the confounding effect of other variables (e.g., parallel interventions, direction of rotation, shift length). The three quick returns differentiated in this review (evening to morning/day, night to evening, morning/day to night) are distinct both from a theoretical and practical point of view, and future studies should make an effort to differentiate between their respective consequences. Moreover, the combined nap and major sleep period in quick returns between morning/day and night shifts should be used in future studies, as this appears to serve as a more accurate indicator of how much rest the workers in total have achieved compared to those with longer changeover periods (Cruz et al. 2003). This issue also has a bearing on the interpretation of previous studies where this is has not been taken into account. 
Future field, laboratory and intervention studies should attempt to compare the three quick returns with longer changeovers to the same respective shifts, which will give a more accurate indication of the specific consequences of short time for recovery between shifts. Both acute and long-term consequences of quick returns need to be studied. The acute consequences of quick returns may include the immediate detrimental impacts on sleep between the shifts, and sleepiness, functioning (e.g., cognitive and motoric) and risk of accidents during the second shift in a quick return. The accumulated detrimental impact of quick returns on these outcomes across the workweek should also be investigated. The long-term consequences of quick returns warrant large-scale prospective studies on physical and mental health-related outcomes, sickness absence and work-life balance. Future studies should also prioritize objective measurement of both shift exposure (e.g., by use of payroll data) and of the various outcome measures, so as to reduce the risk for systematic errors due to subjective reports (Weiss 1995, Podsakoff et al. 2003). Some individuals are able to work shifts without experiencing negative consequences (Saksvik et al. 2011). Research is needed to identify personality variables that predict tolerance of shift characteristics, such as quick returns, so as to inform personnel selection and individualized shift scheduling. Furthermore, an important question for future research is whether female workers experience more detrimental effects of quick returns than males, due to the extra burden placed on the former group in terms of domestic chores (Rotenberg et al. 2008, Silva, Rotenberg, and Fischer 2011). In this regard it should also be noted that females on average report a somewhat longer sleep need than males (Ursin, Bjorvatn, and Holsten 2005). In determining how much recovery time is needed between shifts it seems important to assess the amount of time needed for 
commuting and other activities (time to eat, self-care, social and leisure activities, domestic chores, etc.) during a quick return.

\subsection{Conclusion}

In summary, the results from this review suggest that quick returns shorten sleep duration, cause more disturbed sleep, and in most cases increase reports of sleepiness and fatigue. There are some indications of a detrimental effect of quick returns on the balance between work and private life. The degree to which quick returns disrupt workers general health and wellbeing remains unknown. However, there have been relatively few studies to date examining how quick returns affect sleep and health-related outcomes, and even fewer that have had this as their primary target for investigation. Consequently, the quality of evidence regarding the impact of quick returns remains rather weak, thereby limiting the certainty of these conclusions.

\section{References}

Albertsen, K., A. H. Garde, K. Nabe-Nielsen, Å. M. Hansen, H. Lund, and H. Hvid. 2014.

"Work-life balance among shift workers: results from an intervention study about self- 
rostering." International Archives of Occupational and Environmental Health 87:265274.

Albertsen, K., G. L. Rafnsdóttir, A. Grimsmo, K. Tómasson, and K. Kauppinen. 2008.

"Workhours and worklife balance." Scandinavian Journal of Work Environment \& Health (Suppl 5):14-21.

Axelsson, J., T. Åkerstedt, G. Kecklund, and A. Lowden. 2004. "Tolerance to shift work - how does it relate to sleep and wakefulness?" International Archives of Occupational and Environmental Health 77:121-129.

Baron, K. G., and K. J. Reid. 2014. "Circadian misalignment and health." International review of psychiatry 26:139 -154.

Barton, Jane, and Simon Folkard. 1993. "Advancing versus delaying shift systems." Ergonomics 36:59-64.

Basner, M., K. M. Fomberstein, F. M. Razavi, S. Banks, J. H. William, R. R. Rosa, and D. F. Dinges. 2007. "American time use survey: sleep time and its relationship to waking activities." Sleep 30:1085-1095.

Broomfield, N. M., A. I. Gumley, and C. A. Espie. 2005. "Candidate Cognitive Processes in Psychophysiologic Insomnia." Journal of Cognitive Psychotherapy: An International Quarterly 19:3-15.

Costa, G., M. M. Anelli, G. Castellini, S. Fustinoni, and L. Neri. 2014. "Stress and sleep in nurses employed in "3 x 8" and "2 x 12" fast rotating shift schedules." Chronobiology International 12:1-10.

Costa, G., E. Haus, and R. Stevens. 2010. "Shift work and cancer - considerations on rationale, mechanisms, and epidemiology." Scandinavian Journal of Work Environment \& Health 36:163-179. 
Cruz, C., and P. Della Rocco. 1995. Sleep patterns in air traffic controllers working rapidly rotating shifts: A field study. Washington, DC: Federal Aviation Administration, Office of Aviation Medicine.

Cruz, Crystal, Cristy Detwiler, Thomas Nesthus, and Albert Boquet. 2003. "Clockwise and counterclockwise rotating shifts: Effects on sleep duration, timing, and quality." Aviation, Space, and Environmental Medicine 74 (6):597-605.

Della Rocco, P., and C. Cruz. 1995. Shift work, age, and performance: Investigation of the 2-2-1 shift schedule used in air traffic control facilities I. The sleep/wake cycle. Washington, DC: Federal Aviation Administration, Office of Aviation Medicine.

Della Rocco, P., and C. Cruz. 1996. Shift work, age, and performance: Investigation of the 2-2-1 shift schedule used in air traffic control facilities II. Performance Washington, DC: Federal Aviation Administration, Office of Aviation Medicine.

Edwards, P., M. Clarke, C. DiGuiseppi, S. Pratap, I. Roberts, and R. Wentz. 2002. "Identification of randomized controlled trials in systematic reviews: accuracy and reliability of screening records." Statistics in Medicine 21:1635-1640.

Eldevik, M. F., E. Flo, B. E. Moen, S. Pallesen, and B. Bjorvatn. 2013. "Insomnia, Excessive Sleepiness, Excessive Fatigue, Anxiety, Depression and Shift Work Disorder in Nurses Having Less than 11 Hours in-Between Shifts." PLoS One 8:e70882.

European Parliament, Council of the European Union. 2003. "Directive 2003/88/EC of the European Parliament and of the Council of 4 November 2003 concerning certain aspects of the organisation of working time." http://eur-lex.europa.eu/legalcontent/EN/TXT/?uri=CELEX:32003L0088.

Flo, E., S. Pallesen, N. Magerøy, B. E. Moen, J. Grønli, I. H. Nordhus, and B. Bjorvatn. 2012. "Shift work disorder in nurses - assessment, prevalence and related health problems." PLoS One 7:e33981. 
Flo, E., S. Pallesen, B. E. Moen, S. Waage, and B. Bjorvatn. 2014. "Short rest periods between work shifts predict sleep and health problems in nurses at 1-year follow-up." Occupational and Environmental Medicine 71:555-561.

Gan, Y., C. Yang, X. Tong, H. Sun, Y. Cong, X. Yin, L. Li, S. Cao, X. Dong, Y. Gong, O. Shi, J. Deng, H. Bi, and Z. Lu. 2014. "Shift work and diabetes mellitus: a meta-analysis of observational studies." Occupational and Environmental Medicine 0:1-7. doi: 10.1136/oemed-2014-102150.

Geiger-Brown, J., A. Trinkoff, and V. E. Rogers. 2011. "The impact of work schedules, home, and work demands on self-reported sleep in registered nurses." Journal of Occupational and Environmental Medicine 53:303-307.

Haines, V. Y., A. Marchand, V. Rousseau, and A. Demers. 2008. "The mediating role of work-tofamily conflict in the relationship between shiftwork and depression." Work Stress 22:341e56.

Hakola, T., M. Paukkonen, and T. Pohjonen. 2010. "Less quick returns--greater well-being." Industrial Health 48:390-394.

Holdcroft, A. 2007. "Gender bias in research: how does it affect evidence based medicine?" Journal of the Royal Society of Medicine 100:2-3.

Härmä, M., M. Sallinen, R. Ranta, P. Mutanen, and K. J. Muller. 2002. "The effect of an irregular shift system on sleepiness at work in train drivers and railway traffic controllers." Journal of Sleep Research 11:141-151.

ILO. 1995. Conditions of Work Digest: Working time around the world.

Johnson, J. V., and J. Lipscomb. 2006. "Long working hours, occupational health and the changing nature of work organization." American Journal of Industrial Medicine 49:921-926.

Kandolin, I., and O. Huida. 1996. "Individual flexibility: an essential prerequisite in arranging shift schedules for midwives." Journal of Nursing Management 4:213-7. 
Karhula, K., M. Harma, M. Sallinen, C. Hublin, J. Virkkala, M. Kivimaki, J. Vahtera, and S. Puttonen. 2013. "Association of job strain with working hours, shift-dependent perceived workload, sleepiness and recovery." Ergonomics 56:1640-1651.

Kecklund, G., and T. Åkerstedt. 1995. "Effects of timing of shifts on sleepiness and sleep duration." Journal of Sleep Research 4:47-50.

Knauth, P. 1996. "Designing better shift systems." Applied Ergonomics 27:39-44.

Knauth, P., E. Kiesswetter, W. Ottman, M. Karvonen, and J. Rutenfranz. 1983. "Time-budget studies of policemen in weekly or swiftly rotating shift systems." Applied Ergonomics $14: 247-252$.

Knutsson, A. 2003. "Health disorders of shift workers." Occupational Medicine 53:103-108.

Knutsson, A., and H. Bøggild. 2010. "Gastrointestinal disorders among shift workers." Scandinavian Journal of Work Environment \& Health 36:85-95.

Kurumatani, Norio, Shigeki Koda, Shingo Nakagiri, Akinori Hisashige, Kazuhiro Sakai, Yoshio Saito, Hideyasu Aoyama, Makihiko Dejima, and Tadashige Moriyama. 1994. "The effects of frequently rotating shiftwork on sleep and the family life of hospital nurses." Ergonomics 37:995-1007.

Lowden, A., G. Kecklund, J. Axelsson, and T. Åkerstedt. 1998. "Change from an 8-hour shift to a 12-hour shift, attitudes, sleep and performance." Scandinavian Journal of Work, Environment \& Health 24 (Supplement 3):69-75.

Macdonald, I. I., L. Smith, S. L. Lowe, and S. Folkard. 1997. "Effects on Accidents of Time into Shift and of Short Breaks between Shifts." International Journal of Occupational Medicine 3 (Supplement 2):S40-S45.

Marquié, J.-C., P. Tucker, S. Folkard, C. Gentil, and D. Ansiau. 2014. "Chronic effects of shift work on cognition: findings from the VISAT longitudinal study." Occupational and Environmental Medicine. doi: 10.1136/oemed-2013-101993. 
Mateen, F. J., J. Oh, A. I. Tergas, N. H. Bhayani, and B. B. Kamdar. 2013. "Titles versus titles and abstracts for initial screening of articles for systematic reviews." Clinical Epidemiology 5:89-95.

Merkus, S. L., D. A. van, K. A. Holte, M. Labriola, T. Lund, W. van Mechelen, and A. J. van der Beek. 2012. "The association between shift work and sick leave: a systematic review.' Occupational and Environmental Medicine 69:701-712.

Monk, T. H., and D. J. Buysse. 2013. "Exposure to shift work as a risk factor for diabetes." Journal of Biological Rhythms 28:356-359.

Podsakoff, P. M., S.B. MacKenzie, J. Y. Lee, and N. P. Podsakoff. 2003. "Common method biases in behavioral research: a critical review of the literature and recommended remedies." Journal of Applied Psychology 88:879-903.

Rotenberg, L., L. F. Portela, B. Banks, R. H. Griep, F. M. Fischer, and P. Landsbergis. 2008. "A gender approach to work ability and its relationship to professional and domestic work hours among nursing personnel." Applied Ergonomics 39:646-652.

Ruggiero, J. S., and N. S. Redeker. 2014. "Effects of napping on sleepiness and sleep-related performance deficits in night-shift workers. A systematic review." Biological Research for Nursing 16:134-142.

Saito, Y., and K. Kogi. 1978. "Psychological conditions of working night and subsequent day shifts with short sleep hours between them." Ergonomics 21:871.

Saksvik, I. B., B. Bjorvatn, H. Hetland, G. M. Sandal, and S. Pallesen. 2011. "Individual differences in tolerance to shift work--a systematic review." Sleep Medicine Reviews $15: 221-235$

Sallinen, M., M. Harma, P. Mutanen, R. Ranta, J. Virkkala, and K. Muller. 2003. "Sleep-wake rhythm in an irregular shift system." Journal of Sleep Research 12:103-112. 
Sallinen, M., and G. Kecklund. 2010. "Shift work, sleep, and sleepiness - differences between shift schedules and systems." Scandinavian journal of work, environment \& health 36:121-33.

Schroeder, D. J., R. R. Rosa, and L. A. Witt. 1998. "Some effects of 8- vs. 10-hour work schedules on the test performance/alertness of air traffic control specialists." International Journal of Industrial Ergonomics 21:307-321.

Schroeder, D., R. Rosa, and L. Witt. 1995. Effects of 8-versus 10-hour work schedules on the performance/alertness of air traffic control specialists. Washington, DC: Federal Aviation Administration, Office of Aviation Medicine.

Signal, T., and Philippa H. Gander. 2007. "Rapid counterclockwise shift rotation in air traffic control: Effects on sleep and night work." Aviation, Space, and Environmental Medicine 78:878-885.

Silva, A. A., L. Rotenberg, and F. M. Fischer. 2011. "Nursing work hours: individual needs versus working conditions." Revista De Saúde Pública 45:1117-1126.

Spencer, M. B., K. A. Robertson, and S. Folkard. 2006. The development of a fatigue/risk index for shiftworkers. Research Report 446. London, United Kingdom: Health \& Safety Executive.

Tucker, P., E. Bejerot, G. Kecklund, G. Aronsson, and T. Åkerstedt. 2015. "The impact of work time control on physicians' sleep and well-being." Applied Ergonomics 47:109-116.

Tucker, P., M. Brown, A. Dahlgren, G. Davies, P. Ebden, S. Folkard, H. Hutchings, and T. Åkerstedt. 2010. 'The impact of junior doctors' worktime arrangements on their fatigue and well-being." Scandinavian Journal of Work Environment \& Health 36:458-465.

Tucker, P., L. Smith, I. Macdonald, and S. Folkard. 2000. "Effects of direction of rotation in continuous and discontinuous 8 hour shift systems." Occupational and Environmental Medicine 57:678-684. 
Ursin, R., B. Bjorvatn, and F. Holsten. 2005. "Sleep duration, subjective sleep need, and sleep habits of 40- to 45-year-olds in the Hordaland Health Study." Sleep 28:1260-1269.

Van Dongen, H. P. A., G. Maislin, J. M. Mullington, and D. F. Dinges. 2003. "The cumulative cost of additional wakefulness: dose-response effects on neurobehavioral functions and sleep physiology from chronic sleep restriction and total sleep deprivation." Sleep 2:117126.

v Vogel, M., T. Braungardt, W. Meyer, and W. Schneider. 2012. "The effects of shift work on physical and mental health." Journal of Neural Transmission 119:1121-1132.

Vyas, M. V., A. X. Garg, A. V. Iansavichus, J. Costella, A. Donner, L. E. Laugsand, I. Janszky, M. Mrkobrada, G. Parraga, and D. G. Hackam. 2012. "Shift work and vascular events: systematic review and meta-analysis." BMJ 345:e4800.

Wang, X-S., M. E. G. Armstrong, B. J. Cairns, T. J. Key, and Travis. 2011. "Shift work and chronic disease: the epidemiological evidence." Occupational Medicine 61:78-89.

Weiss, N. S. 1995. "Analytic approaches for dealing with possible recall bias in case-control 口kerstedt, T., G. Kecklund, and A. Knutsson. 1991. "Spectral analysis of sleep

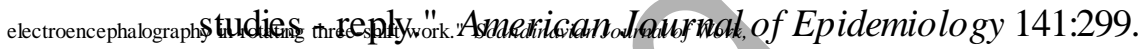


Hits after initial searches ( $\mathrm{N}=2769)$ :

- Web of Science: 1214

- Pubmed: 1100

- PsycINFO: 455

Sorting for article and

deleting duplicates

$(\mathrm{n}=930)$

Potentially ełgible study

reports

(n = 1839)

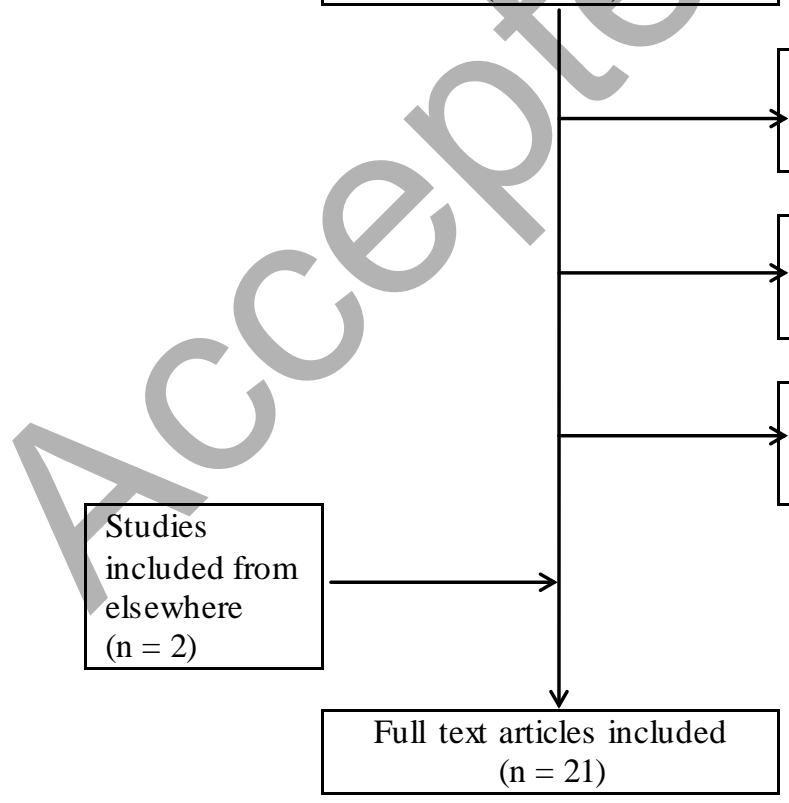

Excluded due to:

- Deemed not relevant

- Review/Commentary

- Non-English

- Not published in peer review journal

- Not possible to interpret the relation of $\mathrm{QR}$ and health-related outcome

Excluded based on reading full text

$(n=59)$

$\rightarrow$ - Split-shift / Sea-watch systems 
Figure 1. Literature search and selection on quick returns and health-related outcome.

Table 1. Literature review summary of studies on the relationship between quick returns and health.

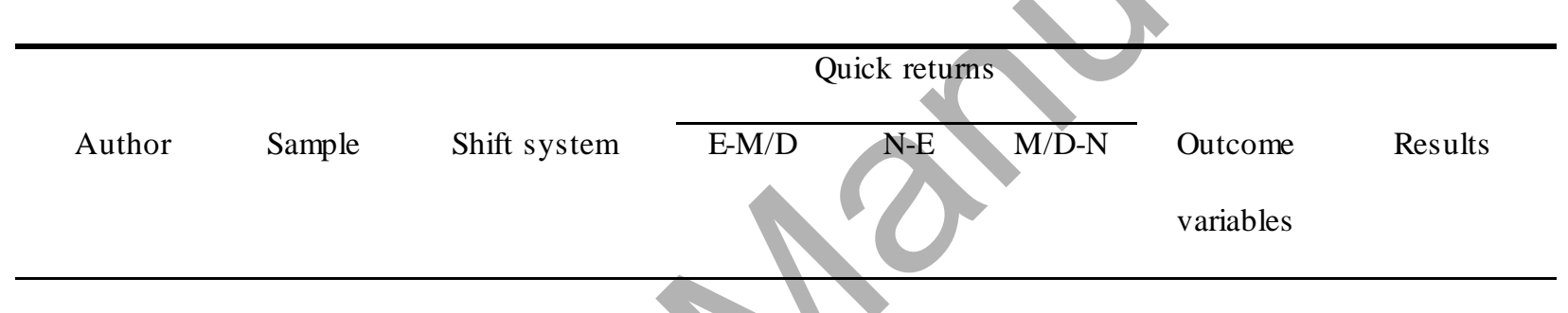

Field

studies:

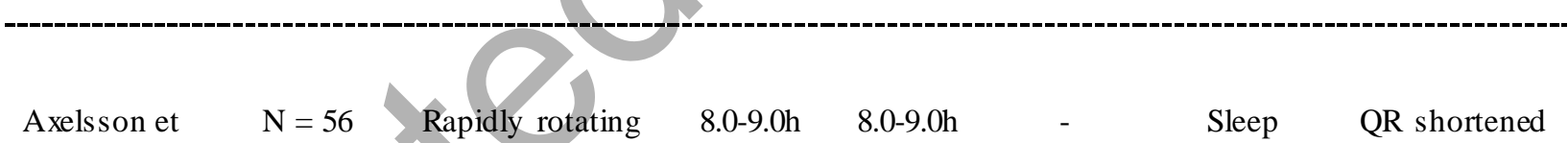

al. (2004)

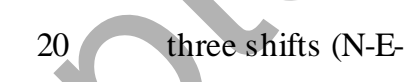

female M) with two quick

36 males returns within

36.0h. 8.0-9.0h 8.0-9.0h $\quad-\quad$ Sleep QR shortened

(actigraphy) sleep duration

Sleepiness to $4.8 \mathrm{~h}(\mathrm{~N}-\mathrm{E})$

and 5.5h (E-

M), relative

to a reported

habitual sleep

need of $8 \mathrm{~h}$

and a

recovery 
sleep of 8.6h.

QR increased

sleepiness.

Costa et al. $\quad \mathrm{N}_{\text {field }}=$

(2014)

30

17

compared to $2 \mathrm{x} 12$

female schedules.

13 male

34.3 yrs.

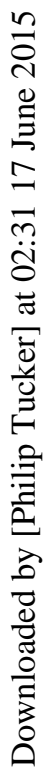

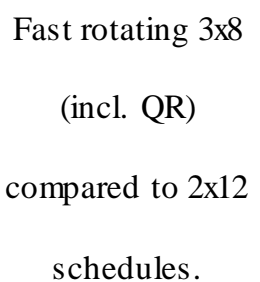

$10.0 \mathrm{~h}$

7.0h

Slee (actigraphy) M shifts

Sleepiness reduced sleep

Sleep quality and

quality sleep duration

to $5.6 \mathrm{~h}(7.8 \mathrm{~h}$

on rest days).

Sleepiness

was higher

with QR (3x8

system) to

morning and

night shifts

compared to

longer

changeovers

to these shifts

(2x12

system).

Karhula et al.

$\begin{array}{cr}\mathrm{N}=95 & \text { Three shift } \\ \text { All } & \text { system. } \\ \text { female } & \end{array}$

9.9h

Sleepiness

A high job

(2013)

47.0 yrs.

$\begin{array}{cl}\text { Physical } & \text { strain group } \\ \text { and mental } & \text { had more } \\ \text { workload } & \text { quick returns }\end{array}$




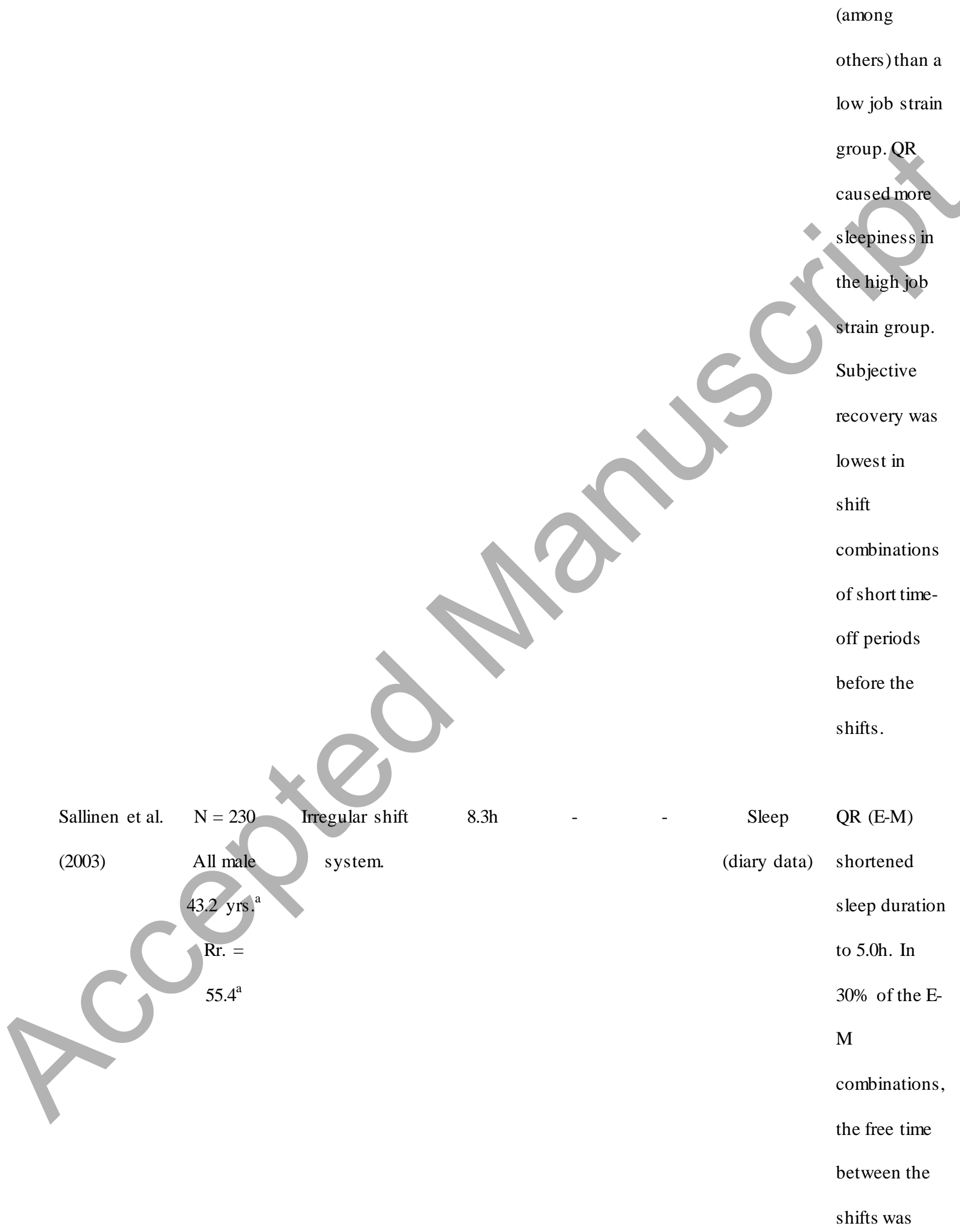


shorter than

the subjects'

mean sleep

need.

$\begin{array}{lrr}\text { Signal and } & \mathrm{N}=28 & \text { Counterclockwise } \\ \text { Gander } & 9 \text { female } & \text { rapidly rotating } \\ \text { (2007) } & 19 \text { male } & \text { schedule } \\ & 35.4 \text { yrs. }^{\text {a }} & \text { (afternoon, day, } \\ & \text { Rr. }= & \text { morning, and } \\ & 78.0 \% & \text { night shift). }\end{array}$

11.0h

Sleep/nap Ninety

(actigraphy percent

and sleep slept/napped

diary) in the $\mathrm{QR}$

from M/D-to-

$\mathrm{N}$, with an

average

duration of

2.2h.

Field and laboratory

study:

Härmä et al.

(2002)

All male

43.2 yrs.

Rr. =

$55.4^{\mathrm{a}}$
Sleepiness $\quad$ QR of $<=8.0 \mathrm{~h}$

system.

$<$ 8.0h

$<8.0 \mathrm{~h} \quad<8.0 \mathrm{~h}$

$\begin{array}{ll}\text { Sleepiness } & \text { QR of }<=8.0 \mathrm{~h} \\ \text { Napping } & \text { from M/D-to- } \\ & \text { N was } \\ & \text { associated } \\ & \text { with a } \\ & \text { smaller risk } \\ & \text { of sleepiness } \\ & \text { than } \\ & \text { changeover }\end{array}$
Napping from M/D-to-
$\mathrm{N}$ was
changeover


of $>=16.0 \mathrm{~h}$.

Sixty two

percent of

QR-subjects

took a nap

before the

night shift

compared to

27\% non-QR.

Laboratory

study:

Cruz et al.

$\mathrm{N}=28$

Rapidly rotating

$8.0 \mathrm{~h}$

$8.0 \mathrm{~h}$

Sleep Sleep

(2003)

16 advancing (with

(actigraphy duration was

female QR) compared to

and sleep $\quad 5.5 \mathrm{~h}$ for $\mathrm{QR}$

12 male delaying three

diary) (E-M) and

40.9 yrs. $^{\text {a }}$ shift.

5.6h for non-

Rr. =

QR to

93.3

morning

shift, not

significant.

Sleep/nap

duration was

2.8h for QR

(M-N) and

1.5h for non-

QR to night 


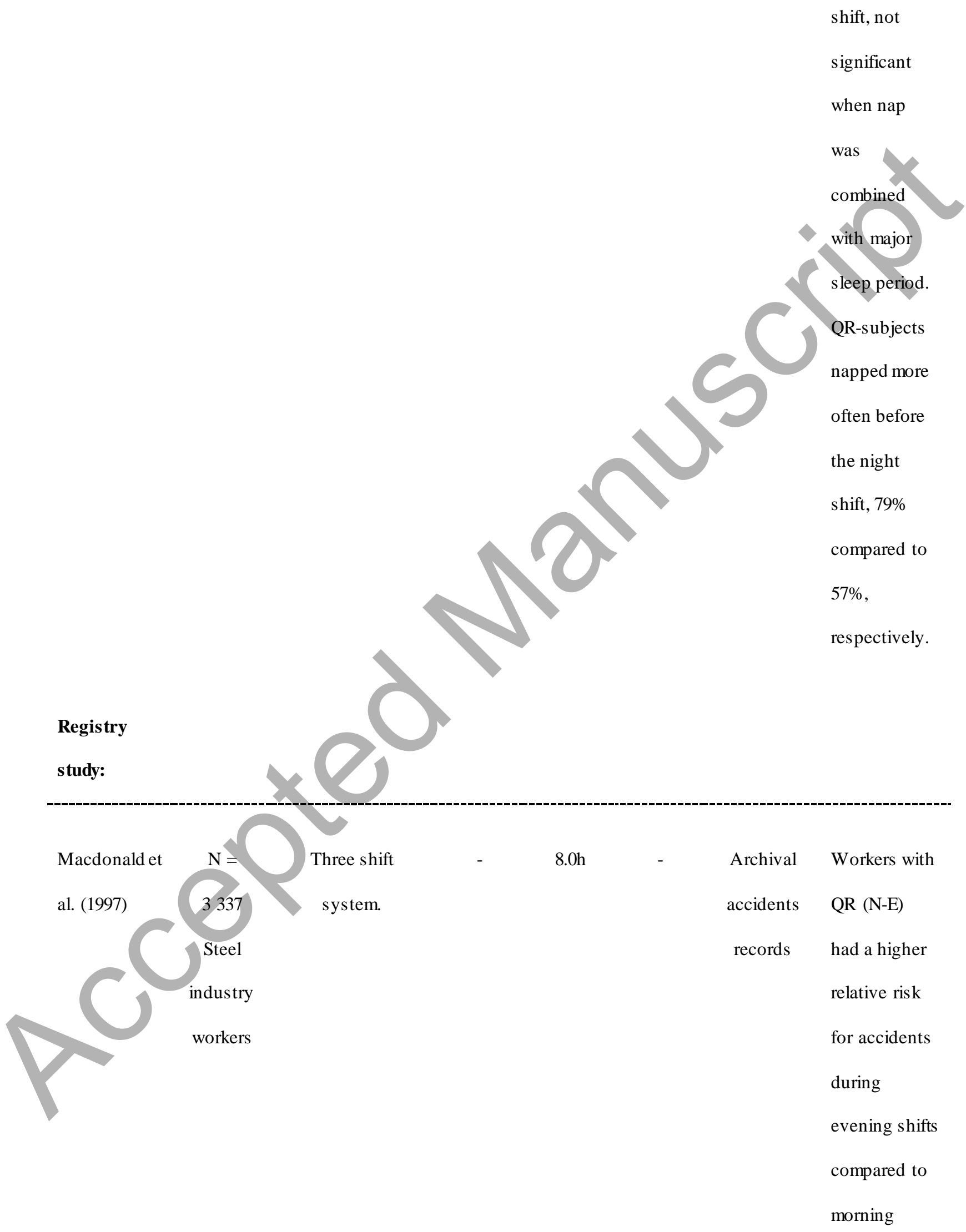


shifts,

relative to

workers

without QR

Survey

studies:

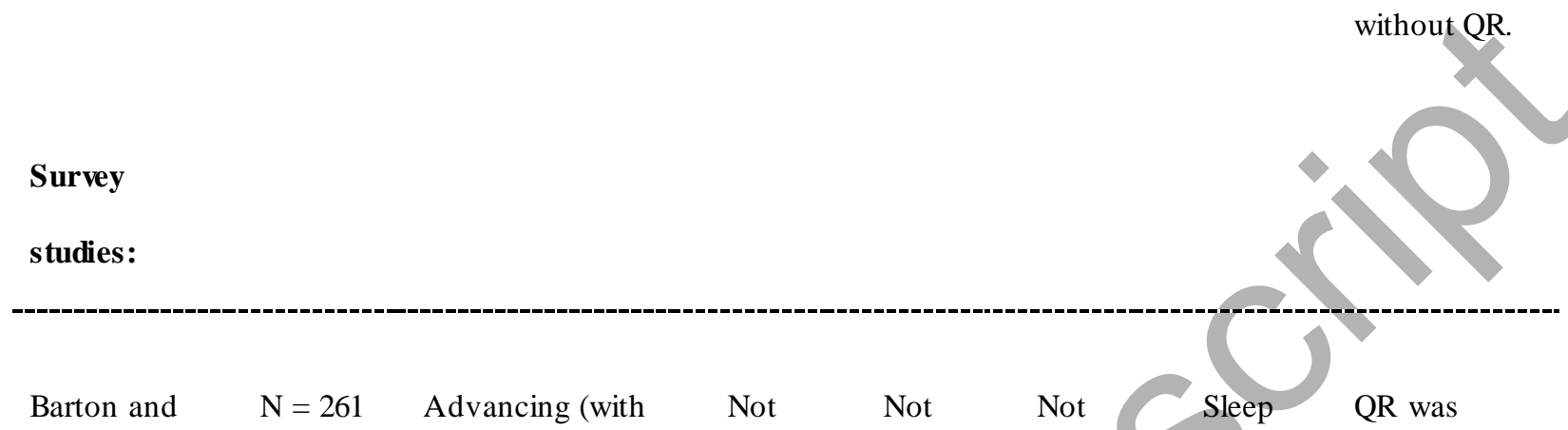

Folkard 18 and without QR of specified specified specified Fatigue associated

(1993) female $\quad$ 8.0h) and delaying

242 male shifts were

Mental with reports

1 compared.

unknown

compared.

39.4 yrs.

$\begin{array}{cl}\text { health } & \text { of more } \\ \text { Social } & \text { fatigue, social } \\ \text { disruption } & \text { and domestic } \\ \text { Job } & \text { disruption } \\ \text { satisfaction } & \text { and less job } \\ & \text { satisfaction; } \\ & \text { but not with } \\ & \text { mental } \\ & \text { health-related } \\ & \text { outcome. }\end{array}$

Also,

advancing

shifts without

QR were

associated

with more

sleep 
disturbances

compared to

those with

QR.

$\begin{array}{ccc}\text { Eldevik et al. } & \text { N }=1990 & \text { Permanent } \\ \text { (2013) } & 90,4 \% & \text { schedules and } \\ & \text { female } & \text { rotating two and } \\ & \text { three shifts. } \\ & \text { Rr. }= & \text { Annual number of } \\ & & \\ 38.1 \% & \text { QR }(<=11.0 \mathrm{~h}) .\end{array}$

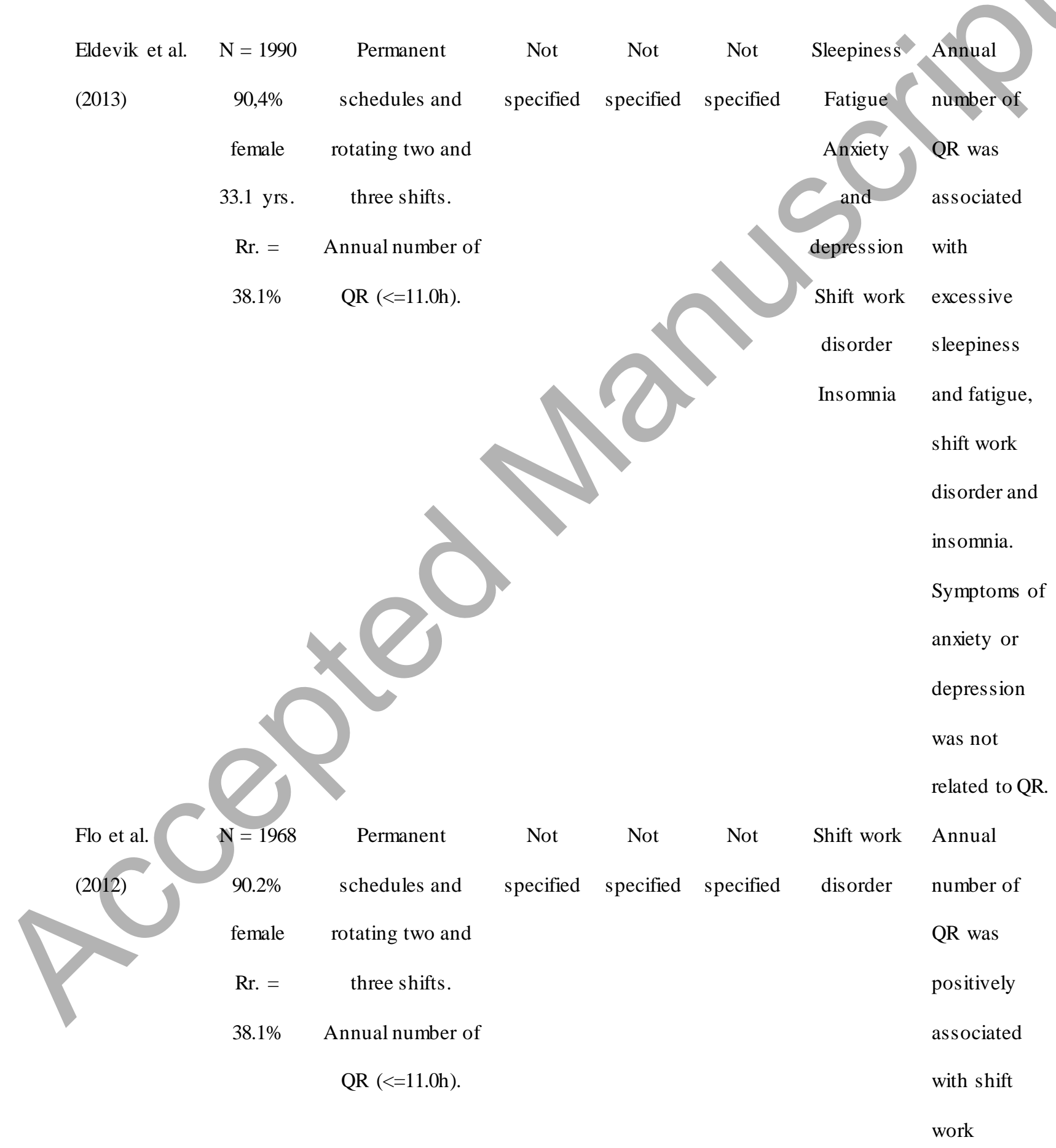


disorder.

$\begin{array}{lcc}\text { Flo et al. } & \mathrm{N}=1224 & \text { Permanent } \\ \text { (2014) } & 90.3 \% & \text { schedules and } \\ \text { (longitudinal) } & \text { female } & \text { rotating two and } \\ & \text { 33.6 yrs. } & \text { three shifts. } \\ & \text { Rr. }= & \text { Annual number of } \\ & \text { 38.1\% } & \text { QR }(<=11.0 \mathrm{~h}) . \\ & \text { and } & \\ & & \\ & & \end{array}$

followed-

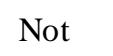

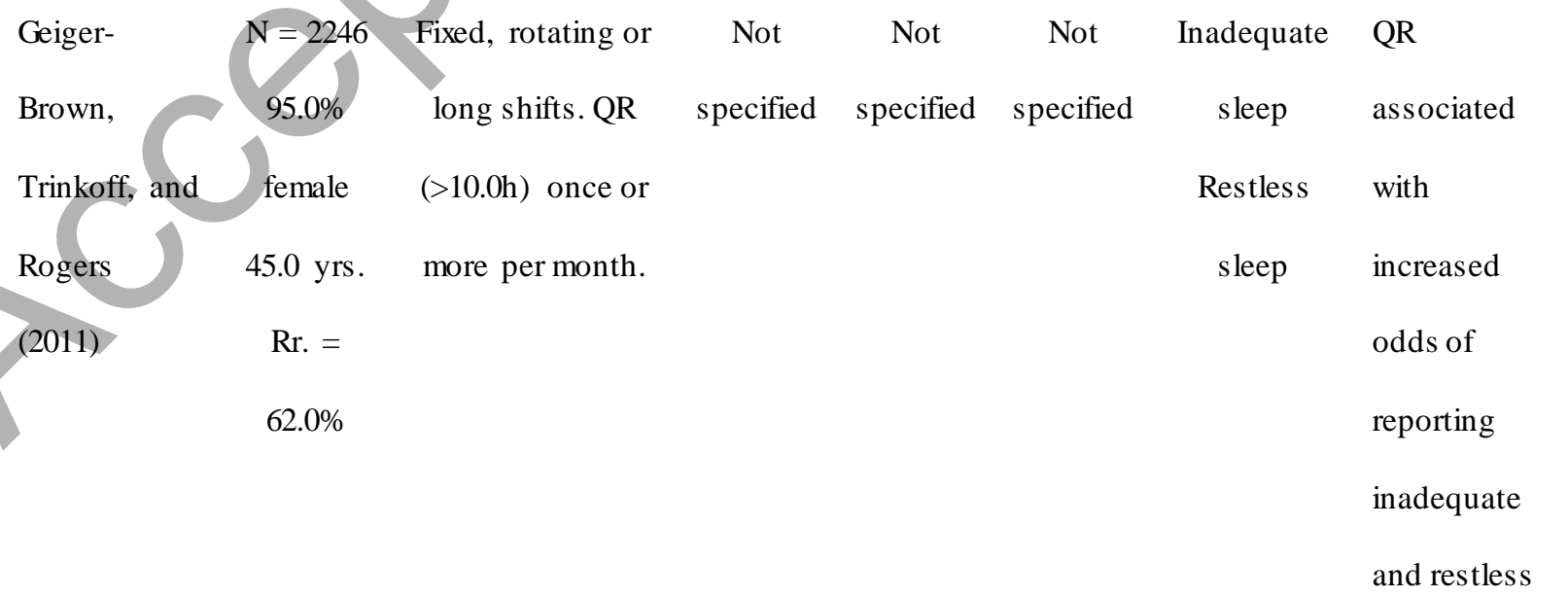


sleep.

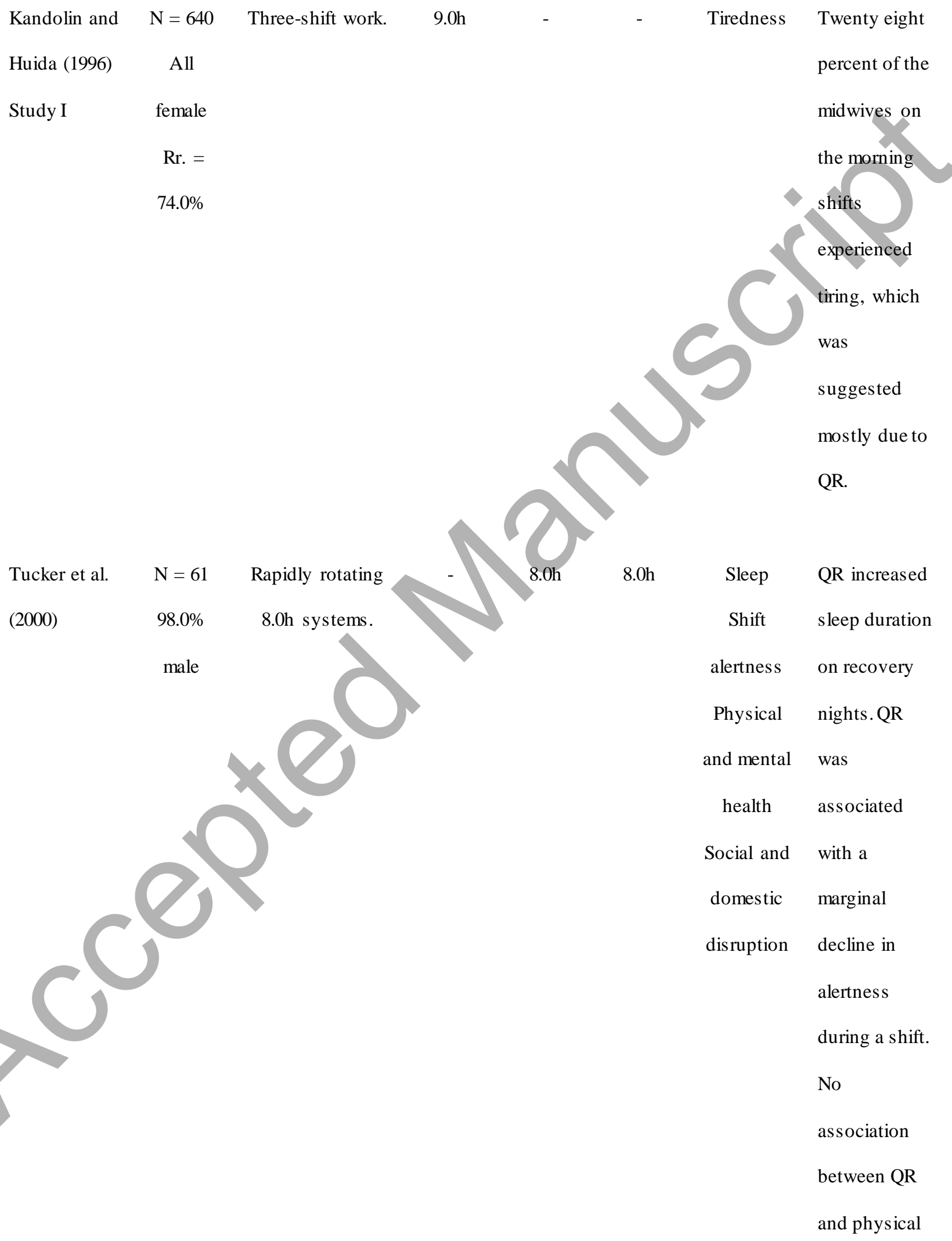




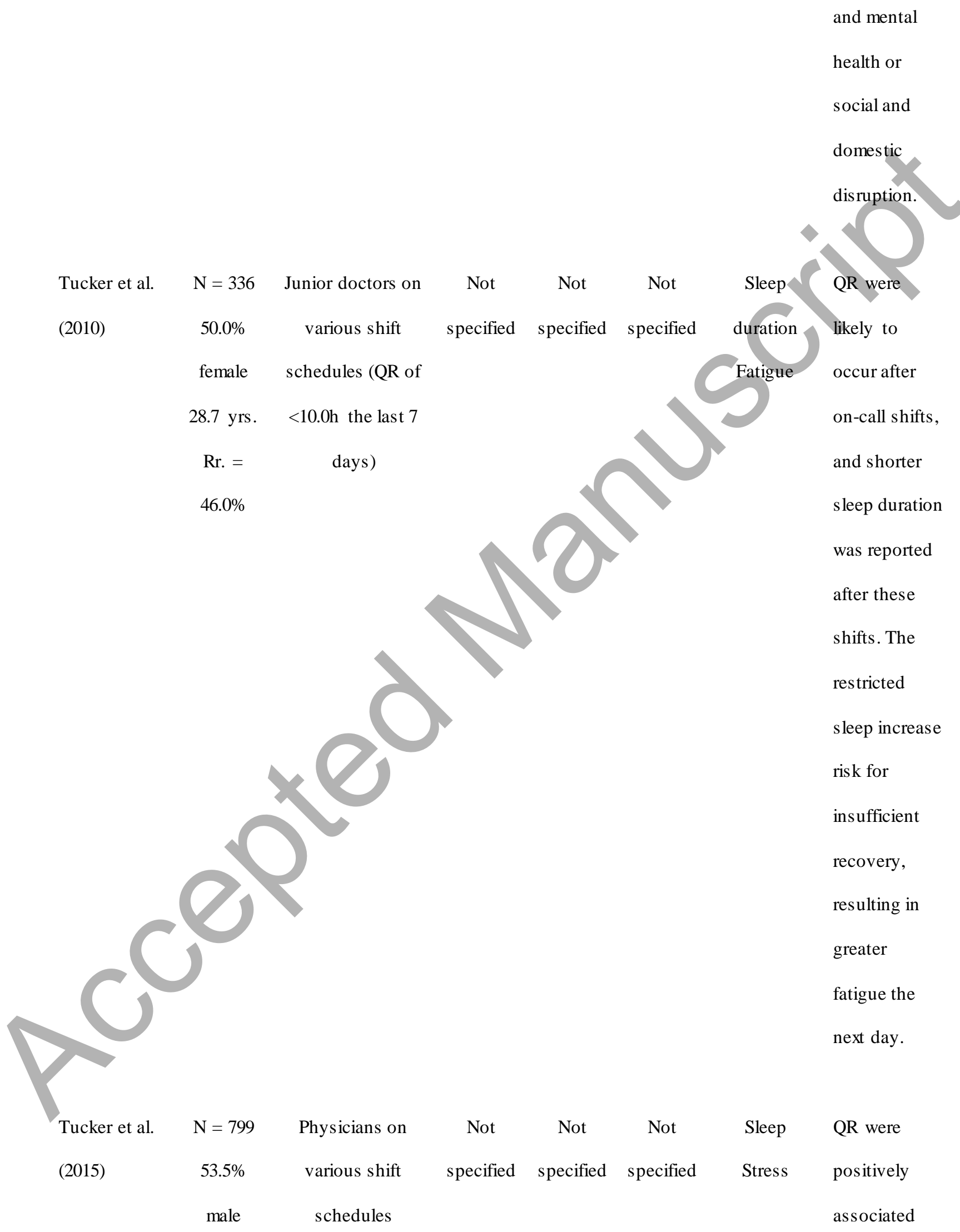


42.9 yrs. (frequency of QR)

Rr. =

$53.1 \%$ with stress

and short

sleep. Work

time control

did not

moderate the

effects of QR.

\section{Intervention}

\section{studies:}

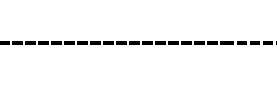

Hakola,

$$
\mathrm{N}=75
$$

A change from

$9.0 \mathrm{~h}$

Paukkonen, $\quad 95 \% \quad$ backward to and Pohjonen

female

(2010) 46.0 yrs. shift rotation.

forward two/three

\section{e}

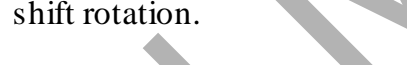

\begin{tabular}{|c|c|}
\hline Sleep & Reduction of \\
\hline Alertness & QR increased \\
\hline General & sleep duration \\
\hline health & from $6.5 h^{1}$ to \\
\hline Leisure- & $7.0 \mathrm{~h}^{1}$, \\
\hline time & improved \\
\hline activities & sleep and \\
\hline Work & alertness, \\
\hline ability & general \\
\hline & health, \\
\hline & wellbeing \\
\hline & both social \\
\hline & and at work, \\
\hline & and leisure \\
\hline & time \\
\hline & activities. \\
\hline
\end{tabular}

Reduced QR 


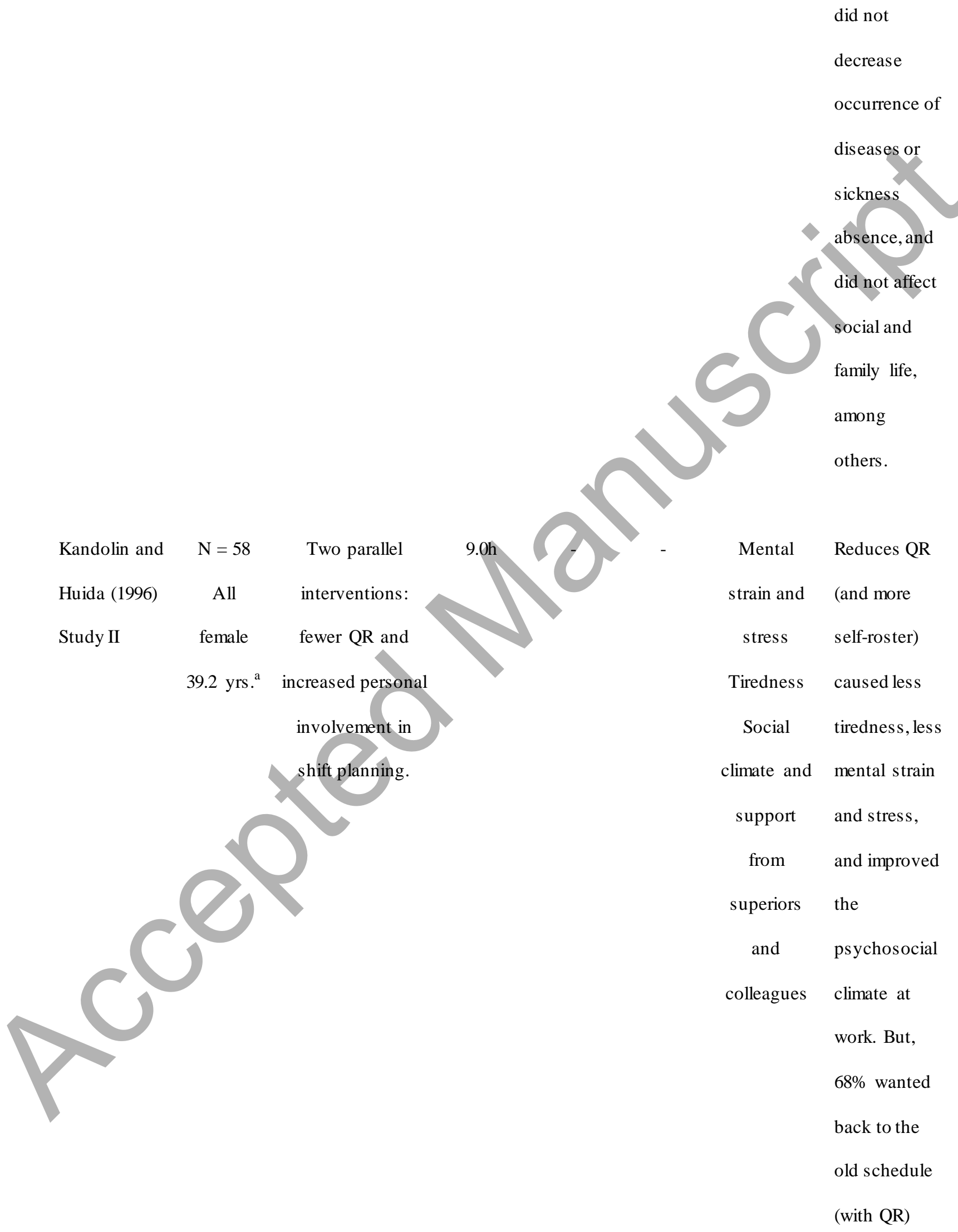




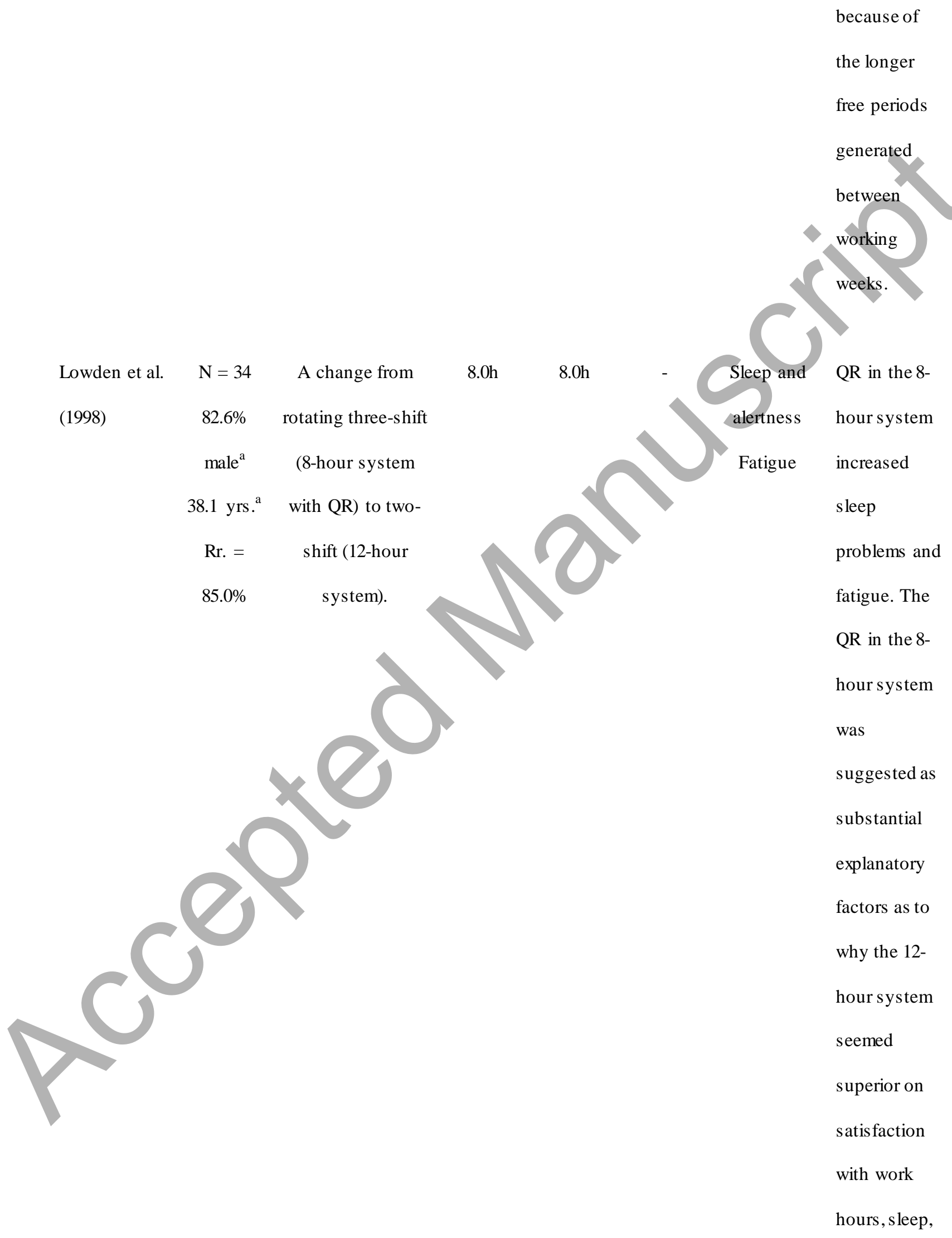


and time for

social

activities .

\section{Time-budget}

studies:

Three shift

8.0h

system.

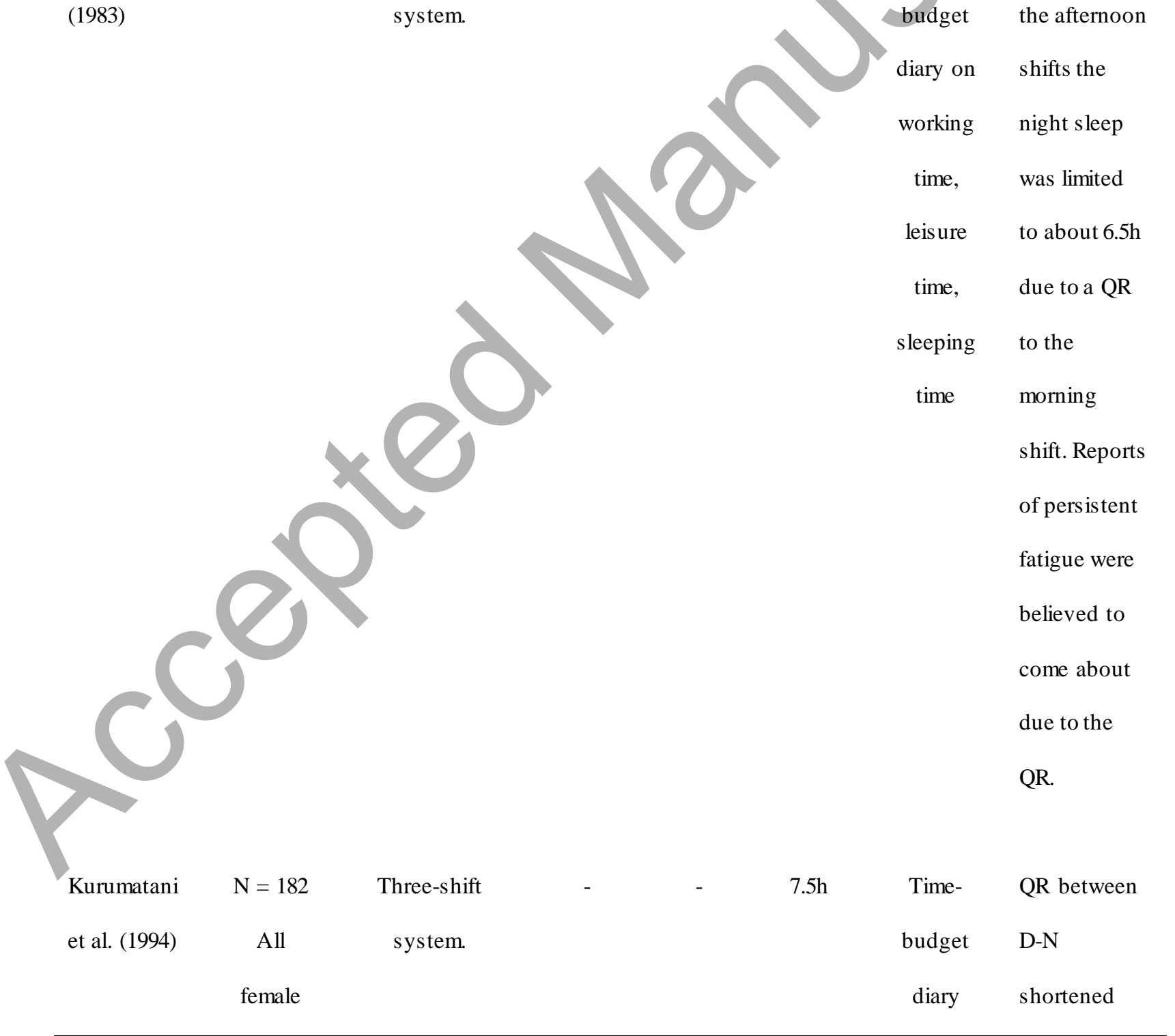




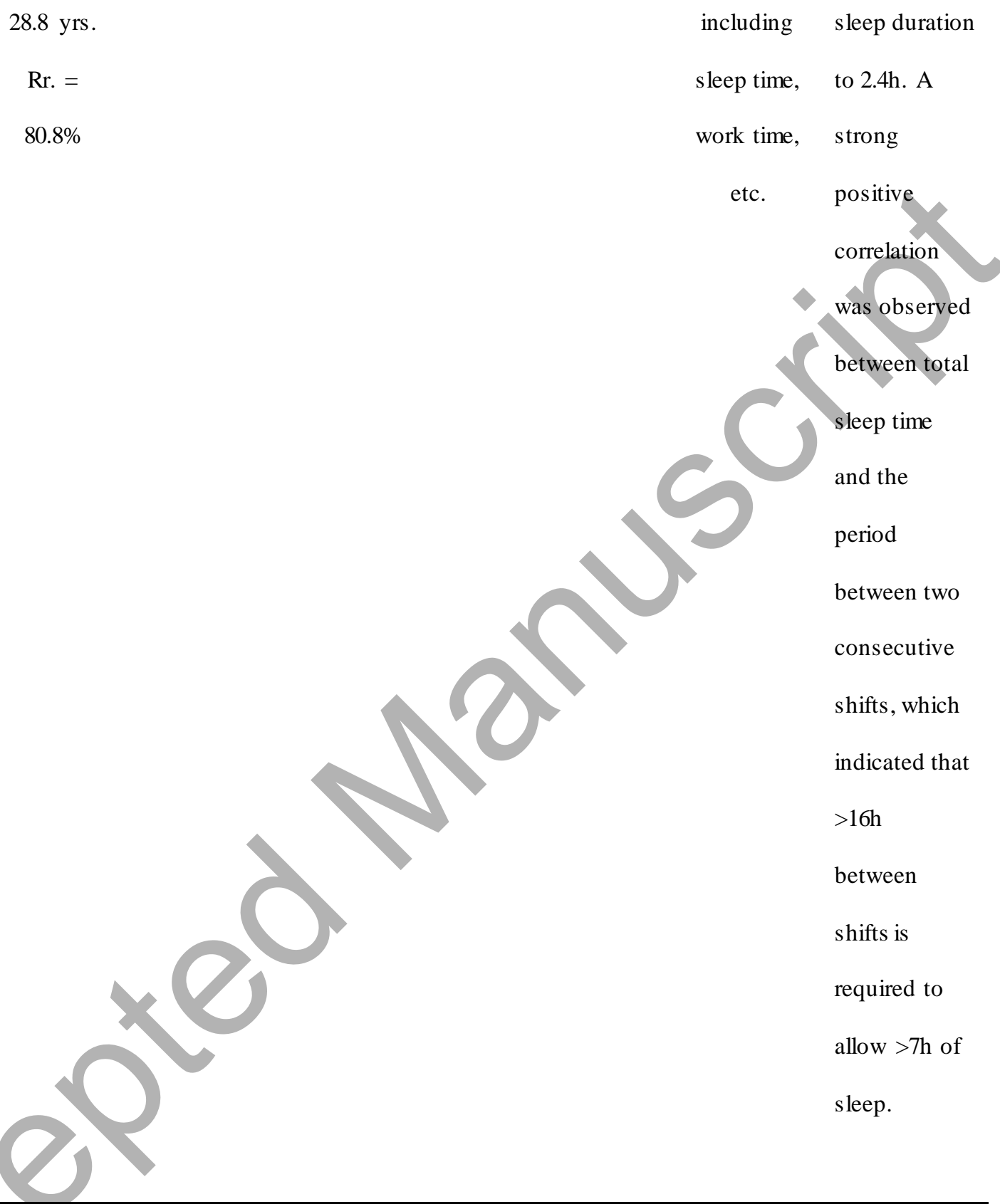

Note. QR = Quick Returns (11 hours or less between two shifts). E-M/D, N-E and M/D-N refer to the quick returns from Evening to Morning/Day, Night to Evening, and Morning/Day to Night, respectively. Rr. is short for Response rate.

${ }^{\mathrm{a}}$ Weighted mean of a given quality that in the original study was reported from two or more sub-groups.

Table 2. Differences in sleep duration between three types of quick returns. 


\begin{tabular}{|c|c|c|c|c|c|}
\hline & \multirow{2}{*}{$\begin{array}{l}\text { Quick } \\
\text { returns } \\
\text { (QR) }\end{array}$} & \multirow{2}{*}{$\begin{array}{c}\text { Sleep } \\
\text { duration } \\
\text { without QR }\end{array}$} & \multicolumn{3}{|c|}{ Sleep duration with $\mathrm{QR}$} \\
\hline & & & $\mathrm{E}$ to $\mathrm{M} / \mathrm{D}$ & $\mathrm{N}$ to $\mathrm{E}$ & $\mathrm{M} / \mathrm{D}$ to $\mathrm{N}$ \\
\hline $\begin{array}{l}\text { Axelsson et al. } \\
\text { (2004) }\end{array}$ & $8.0-9.0 \mathrm{~h}$ & $8.0 \mathrm{~h}^{\mathrm{a}}$ & $5.5 \mathrm{~h}$ & $4.8 \mathrm{~h}$ & - \\
\hline Costa et al. (2014) & $10.0 \mathrm{~h} / 7.0 \mathrm{~h}^{\mathrm{b}}$ & $7.8 \mathrm{~h}$ & $5.6 \mathrm{~h}$ & - & \\
\hline Cruz et al. (2003) & 8.0h & - & $5.5 \mathrm{~h}$ & & $2.8 \mathrm{~h}$ \\
\hline Sallinen et al. (2003) & $8.3 \mathrm{~h}$ & - & $5.0 \mathrm{~h}$ & & - \\
\hline Knauth et al. (1983) & $8.0 \mathrm{~h}$ & - & & - & - \\
\hline $\begin{array}{l}\text { Hakola, Paukkonen, } \\
\text { and Pohjonen (2010) }\end{array}$ & $9.0 \mathrm{~h}$ & $7.0 \mathrm{~h}^{\mathrm{c}}$ & & - & - \\
\hline $\begin{array}{l}\text { Signal and Gander } \\
\text { (2007) }\end{array}$ & $11.0 \mathrm{~h}$ & & - & - & $2.2 \mathrm{~h}$ \\
\hline $\begin{array}{l}\text { Kurumatani et al. } \\
\text { (1994) }\end{array}$ & & & - & - & $2.4 \mathrm{~h}$ \\
\hline
\end{tabular}

Notes: QR = Quick Returns; E = Evening shift; M/D = Morning/Day shift; $\mathrm{N}=$ Night shift. ${ }^{\mathrm{a}}$ Reported habitual sleep need. ${ }^{\mathrm{b}} \mathrm{Quick}$ returns from E-M $=10.0 \mathrm{~h}$ and from $\mathrm{M}-\mathrm{N}=$ 7.0h. ${ }^{\text {c}}$ The weighted average sleep duration of the three age groups studied by Hakola et al.

Table 3. Summary of associations of quick returns on health-related outcome. 
Three types of quick returns

\begin{tabular}{|c|c|c|c|c|}
\hline & $\mathrm{E}$ to $\mathrm{M} / \mathrm{D}$ & $\mathrm{N}$ to $\mathrm{E}$ & $\mathrm{M} / \mathrm{D}$ to $\mathrm{N}$ & $\begin{array}{l}\text { QR type not } \\
\text { specified }\end{array}$ \\
\hline $\begin{array}{l}\text { Quick returns associated with } \\
\text { detrimental effects on: }\end{array}$ & 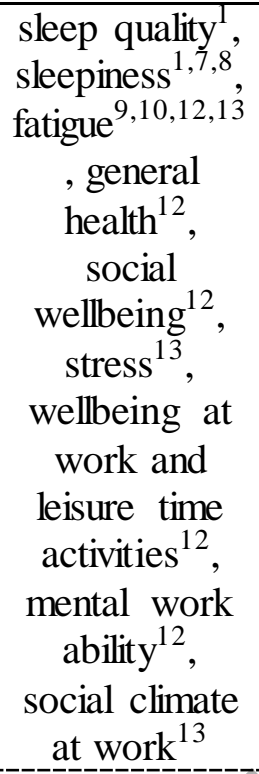 & $\begin{array}{l}\text { sleepiness }^{7} \text {, } \\
\text { fatigue }^{10,14} \text {, } \\
\text { accidents*15 }^{*}\end{array}$ & $\begin{array}{l}\text { sleepiness }^{1} \text {, } \\
\text { fatigue }^{9,14}\end{array}$ & 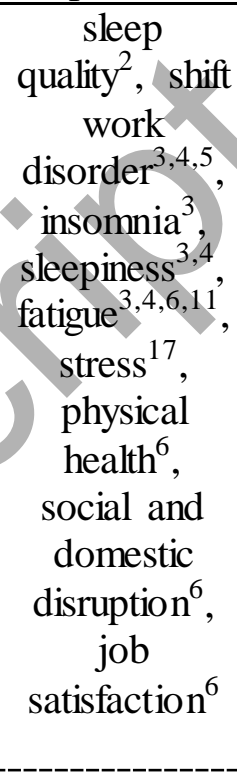 \\
\hline $\begin{array}{l}\text { Quick returns associated with } \\
\text { beneficial effects on: }\end{array}$ & & & sleepiness $^{1 \overline{6}}$ & $\begin{array}{c}\text { sleep } \\
\text { disturbances }\end{array}$ \\
\hline $\begin{array}{l}\text { Quick returns not } \\
\text { associated with effects on: }\end{array}$ & $\begin{array}{l}\text { occurrence of } \\
\text { diseases }^{12} \text {, } \\
\text { sickness }^{12} \\
\text { absence }^{12} \text {, } \\
\text { general work }^{12} \text { ability } \\
\text { social and }^{12} \\
\text { family life }^{12}\end{array}$ & $\begin{array}{l}\text { physical } \\
\text { health }^{14} \text {, } \\
\text { social and } \\
\text { domestic }^{14}\end{array}$ & $\begin{array}{l}\text { physical } \\
\text { health }^{14} \text {, } \\
\text { social and } \\
\text { domestic } \\
\text { disruption }^{14}\end{array}$ & $\begin{array}{c}\text { mental } \\
\text { health }^{3,4,6}\end{array}$ \\
\hline
\end{tabular}

Notes: QR = Quick Returns; $\mathrm{E}=$ Evening shift; $\mathrm{M} / \mathrm{D}=$ Morning/Day shift; $\mathrm{N}=$ Night shift.

*A retrospective re-analysis of the results called into doubt the interpretation of the findings in terms of accidents (Spencer, Robertson, and Folkard 2006).

${ }^{1}$ Costa et al. (2014)

${ }^{2}$ Geiger-Brown et al. (2011)

${ }^{3}$ Eldevik et al. (2013)

${ }^{4}$ Flo et al. (2014)

${ }^{5}$ Flo et al. (2012)
${ }^{6}$ Barton and Folkard (1993)

${ }^{7}$ Axelsson et al. (2004)

${ }^{8}$ Karhula et al. (2013)

${ }^{9}$ Knauth et al.

$(1983)^{10}$ Lowden et al.

(1998)

\footnotetext{
${ }^{11}$ Tucker et al. (2010)

${ }^{12}$ Hakola et al. (2010)

${ }^{13}$ Kandolin and Huida (1996)

${ }^{14}$ Tucker et al. (2000)

${ }^{15} \mathrm{M}$ acdonald et al. (1997)
}

${ }^{16} \mathrm{Härmä} \mathrm{et} \mathrm{al.}$

(2002) $)^{17}$ Tucker et al. (2015) 